\title{
LA COMPRENSIÓN DE LA VOLUNTAD DE DIOS EN LA OBRA «CAMINO ESPIRITUAL» DEL P. LUIS DE LA PALMA
}

Fecha de recepción: 14 de diciembre de 2017

Fecha de aceptación y versión final: 31 de octubre de 2018

RESUMEN: El artículo comienza recordando la actualidad que tiene la cuestión de la voluntad de Dios y explica que es posible distinguir una comprensión deontotónica y otra agapetónica de la misma. Nos acerca a la comprensión de la voluntad divina en la obra Camino Espiritual del P. Luis de la Palma (1559-1641), ofrece algunos párrafos escogidos y profundiza en la denominación de voluntad de Dios como agrado de Dios. En la segunda parte, cita a otros autores que comparten esta perspectiva: jesuitas del inicio, como Ignacio, Fabro, Javier, Nadal y Borja; y otros contemporáneos a La Palma como Canisio, Alonso Rodríguez, La Puente y Claver. El artículo ofrece las siguientes conclusiones: Cristo vive y se comunica, importancia de cumplir la voluntad divina, relación entre mandamientos y agrado de Dios, luz que esto aporta al fin de los ejercicios y el tesoro espiritual que todavía esconde Luis de La Palma.

PALABRAS CLAVE: jesuitas; Compañía; Palma; agrado; voluntad; espiritualidad; ejercicios.

* Diócesis de Getafe: manuelvargascano@gmail.com; ORCID: http://orcid.org/ 0000-0001-9853-9984 


\section{God's Will in Ignatian Spirituality and it's Understanding in Fr. La Palma's "Camino Espiritual»}

ABSTRACT: The article begins by recalling the relevance of the question of God's will, and it explains that it is possible to distinguish between a deontotonic and an agapetonic understanding of it. It brings us closer to a better comprehension of God's will in La Palma's work Camino Espiritual (1559-1641), it offers us some selected paragraphs, and it deepens into the denomination of God's will as pleasing to God. In the second part, it quotes other authors who share this perspective: the first Jesuits, such as Ignatius, Faber, Javier, Nadal and Borja; and other contemporaries to La Palma, such as Canisus, Rodríguez, La Puente and Claver. The article offers the following conclusions: Christ lives and communicates himself, the value of fulfilling the divine will, the relationship between commandments and to please God, the light that this sheds upon the goal of the Exercises, and the spiritual treasure that La Palma still hides.

KEY WORDS: jesuits; Society; Palma; to please; will; spirituality; exercises.

\section{INTRODUCCIÓN ${ }^{1}$}

La voluntad de Dios es uno de los temas por excelencia de la espiritualidad ignaciana. Javier Melloni afirma que la expresión ignaciana «que su voluntad siempre sintamos y aquélla enteramente cumplamos condensa perfectamente la esencia del carisma ignaciano»².

En efecto, muchos de los conceptos que utiliza la espiritualidad ignaciana tienen como foco de atención la voluntad de Dios: así, por ejemplo, la indiferencia es no dejarse condicionar por afectos desordenados en la búsqueda de la voluntad de Dios; la abnegación es la virtud de no determinarse por voluntad o juicio propios para hallar más fácilmente la voluntad de Dios; los tiempos de elección son momentos o maneras de descubrir la voluntad de Dios; la devoción es el don divino de cumplir con prontitud la voluntad de Dios; la reverencia y acatamiento se expresan respecto a Dios y a su voluntad; el discernimiento consiste en

1 Para las abreviaturas y siglas véase la lista al final del texto del artículo. Al referirnos al texto del libro de los Ejercicios Espirituales de san Ignacio, lo haremos en letra cursiva. Para referirnos a la práctica de estos ejercicios (el hecho de darlos, recibirlos, las actitudes que se requieren, los frutos que se esperan, etc.) lo haremos sin cursiva, en estilo de letra regular.

2 Javier Melloni, "Que su voluntad siempre sintamos y aquélla enteramente cumplamos”, Manresa 324 (2010): 238. 
distinguir lo que viene de Dios en las mociones interiores y motivaciones; y, en palabras del P. Arrupe, también «el verdadero examen de conciencia debe ser la actitud constante de buscar la voluntad de Dios por un contacto ininterrumpido con él $»^{3}$.

Como también sostiene Javier Melloni, en la actualidad se ha replanteado la misma expresión voluntad de Dios. Dice este autor:

«Hoy en día resulta problemática una cierta manera de comprender ese cumplir la voluntad de Dios. Puede evocar una actitud de sumisión ante un Ser todopoderoso que está por encima del ser humano y que impone su voluntad, la cual sólo hay que obedecer» ${ }^{4}$.

No es mi intención explicar por qué la voluntad de Dios no es heterónoma (esta cuestión es abordada por san Juan Pablo II) ${ }^{5}$, pero la cita de Melloni nos permite intuir cuánta trascendencia tiene este asunto.

En este artículo trataremos, en particular, cómo se entiende la voluntad de Dios en perspectiva ignaciana, y cómo enfocó esta cuestión el P. Luis de La Palma en su obra Camino Espiritual. Los motivos del provecho que tiene estudiar esta cuestión son al menos dos: profundizar en el concepto de voluntad de Dios y acercarnos a los escritos de Luis de La Palma. La segunda generación de Padres de la Compañía de Jesús, aunque conocida por los historiadores ${ }^{6}$, no ha suscitado tanto interés en los estudiosos como la generación de los fundadores ${ }^{7}$. Entre los miembros de la segunda generación, hay notables autores de teología ascética y

3 Pedro Arrupe, "Notas sobre el modo de dar los Ejercicios hoy", en La identidad del jesuita en nuestros tiempos (Santander: Sal Terrae, 1981), 234.

4 Melloni, 239.

5 Cf. Juan Pablo II, “Encíclica Veritatis Splendor” n. 41, AAS 85 (1993) 1165-1166.

6 Cf. Antonio Astrain, Historia de la Compañía de Jesús, en la Asistencia de España, vol. IV (Madrid: Imprenta de los sucesores de Rivadeneyra, 1909), 79-91; Ricardo García-Villoslada, Manual de Historia de la Compañía de Jesús (Madrid: Compañía Bibliográfica Española, 1954), 281.367-369. Más bibliografía en: José de Guibert, La espiritualidad de la Compañia de Jesús (Santander: Sal Terrae, 1955), 180-197.

7 Abundante bibliografía sobre los fundadores en: Ignacio Iparraguirre y Manuel Ruiz Jurado, Orientaciones bibliográficas sobre San Ignacio de Loyola, 3 vol. (Roma: IHSI, 1965-1990); José María Azcona, Bibliografía de san Francisco de Javier (Pamplona: Diputación Foral de Navarra, 1952), 274; Carlos Guillermo Plaza, "Bibliografía del B. Fabro", Manresa 69 (1946): 378-385; José Antonio Pérez Rioja, "Una bibliografía en torno al P. Diego Laínez", Celtiberia 15 (1965): 213-243; László Polgar, Bibliographie sur l'histoire de la Compagnie de Jésus 1996-2000 (Roma: IHSI, 2001), 3:87.148-149. 
mística (por ejemplo, Cordeses ${ }^{8}$, Álvarez de Paz ${ }^{9}$, La Puente ${ }^{10}$ y Baltasar Álvarez $\left.{ }^{11}\right)$. Entre ellos, el P. Luis de La Palma es paradigmático, insuficientemente conocido pero muy valioso, y nos permitirá acercarnos a descubrir algunas fuentes teológicas de las que bebieron los autores de dicha generación.

El motivo de escoger el libro Camino Espiritual es porque se adentra en la entraña de los Ejercicios Espirituales de san Ignacio. La obra Historia de la Pasión, denominada por Rodríguez Molero como «la obra cumbre del P. La Palma (...), la más conocida suya» ${ }^{12}$, y calificada por Astrain ${ }^{13}$ como «joya inestimable, tan llena de sólida doctrina como de jugosa devoción $»^{14}$, consiste en meditaciones sobre la Pasión, es decir, un desarrollo de la tercera semana de Ejercicios. Por su parte, la obra Práctica y breve declaración de los Ejercicios es «simplemente un retiro de ocho días sobre los Ejercicios ${ }^{15}$. Camino Espiritual, a pesar de ser una obra incompleta, es un verdadero tratado sobre el libro de los Ejercicios y un cuerpo de doctrina espiritual ${ }^{16}$.

No pretendemos un desarrollo acabado de la cuestión de la voluntad divina, y este asunto ha sido ya abordado desde varias perspectivas en diversas ocasiones ${ }^{17}$ : por citar algunos ejemplos, san Agustín trata esta cuestión en el contexto de la conciliación entre la omnipotencia de Dios y la libertad del hombre ${ }^{18}$. Santo Tomás de Aquino ${ }^{19}$ profundizó en la

8 Cf. Manuel Ruiz Jurado, “Cordeses, Antonio”, en DHCJ, vol. II, 952-953.

9 Cf. E. Fernández, “Álvarez de Paz, Diego”, en DHCJ, vol. I, 94-95.

10 Cf. Camilo Abad, El Venerable P. Luis de la Puente, de la Compañía de Jesús. Sus libros y su doctrina espiritual (Santander: Universidad Pontificia Comillas), 1954.

11 Cf. Manuel Ruiz Jurado, "Álvarez, Baltasar", en DHCJ, vol. I, 91-93.

12 Francisco Xavier Rodríguez Molero, "Introducción”, en Luis de La Palma, Obras (Madrid: BAC, 1967), 72.

13 Cf. Rafael M. a Sanz de Diego, “Astrain, Antonio”, en DHCJ, vol. I, 258-259.

14 Astrain, vol. V, 95.

15 Guibert, 228.

16 Ignacio Iparraguirre, Historia de los Ejercicios de San Ignacio, vol. II (Roma: IHSI, 1955), 109.

17 Cf. Michel Dupuy, "Volonté de Dieu”, en DSp 16, 1248-1269; F. M. Catherinet, "Conformité à la volonté de Dieu", en DSp 2B, 1444-1445; A. Miguel, "Volonté de Dieu”, en Dictionnaire de Théologie Catholique, ed. Emile Amann, Eugène Mangenot, y Eugène Vacant, vol. XV (Paris: Letouzey et Ané, 1950), 3322-3374.

18 Cf. Cf. San Agustín, La ciudad de Dios (Madrid: BAC, 1988), 1:355-357; Id., Enarratio in Psalmum XLIV, n. 17, en PL 36, 503-504.

19 Cf. Santo Tomás de Aquino, Suma de Teología, 4. ${ }^{\text {a }}$ ed. (Madrid: BAC, 2001), $\mathrm{I}^{\mathrm{a}}$, q. 19 , a. 11-12. 
distinción entre voluntad de beneplácito que es, en rigor, el conjunto de las decisiones que Dios ha tomado libre y definitivamente y que necesariamente va a lograr; y la voluntad de signo o voluntad significada, que es aquella que Él manifiesta a las criaturas libres. En el siglo XVI también se avivó la cuestión de la voluntad de Dios a propósito de la predestinación: Luis de Molina y Domingo Báñez explicaron, con mayor o menor acierto, la bondad de la voluntad de Dios -que nos ha predestinado a ser salvados- y el espacio intacto que queda a la libertad humana ${ }^{20}$.

Nuestra intención es acercarnos a la voluntad de Dios tal como la comprendió el P. La Palma, en el contexto más amplio de la espiritualidad ignaciana. Y para ello nos servimos de la distinción tomista de voluntad de beneplácito y voluntad significada porque -como veremos pronto- está presente en la obra de La Palma.

La metodología que he empleado es el análisis semántico, centrando mi atención en la terminología y el campo semántico utilizado por La Palma (es decir, las palabras que aparecen con frecuencia para referirse a lo que, en sentido genérico, denominamos voluntad de Dios). Hemos tratado de encontrar explicación al tono afectuoso (o podríamos llamarlo cordial, entrañable) con el que el P. Luis de La Palma hace referencia a la «voluntad significada» de Dios, así como a algunos precedentes inmediatos de donde provienen estas palabras y las consecuencias que esto tiene para la teología espiritual.

\section{LA VOLUNTAD DE DIOS EN LA OBRA «CAMINO ESPIRITUAL»}

\subsection{El P. Luis de la Palma y sus obras}

La biografía del P. Luis de La Palma ${ }^{21}$ está al alcance del lector en varias obras de carácter histórico. Tenemos una crónica de su trayectoria en

\footnotetext{
20 Cf. José Luis Illanes, y Josep Ignasi Saranyana, Historia de la Teología (Madrid: BAC, 1995), 149-152. 197-198.

21 Luis de La Palma (Toledo, 1560 - Madrid, 1641), sacerdote jesuita. Hizo el noviciado en Alcalá de Henares y Navalcarnero (Madrid). Profesor de Teología en Murcia, dedicó buena parte de su vida a formar nuevos jesuitas. Por su prudencia y humildad fue destinado a tareas de gobierno (rector en Talavera, rector en Madrid, provincial), y ha pasado a la historia por algunas célebres obras de piedad, escritas con un uso elegante de la lengua castellana.
} 
el Diccionario de O'Neill y Domínguez ${ }^{22}$, y otros autores nos ofrecen informaciones sobre él: Andrade, quien lo incluye en el libro que dedica a varones ilustres de la Compañía ${ }^{23}$, Cereceda ${ }^{24}$, Celestino Testore ${ }^{25}$, Leturia ${ }^{26}$, Robert Ricard ${ }^{27}$, Arzubialde (quien cita el libro Camino Espiritual en 11 ocasiones en su tratado sobre los Ejercicios $)^{28}$, Astrain ${ }^{29}$ y otros.

«Para el P. de Guibert esa obra (Camino Espiritual) sería uno de los mejores comentarios de los Ejercicios. Para el P. Iparraguirre, La Palma es el mejor comentador de los Ejercicios. Colodrón no duda en adjudicarle el título de Príncipe de los comentarios de los Ejercicios. Tirso Arellano coincide en llamarle también Príncipe de los comentaristas [...]»30.

Debemos a los PP. Abad ${ }^{31}$ y Rodríguez Molero ${ }^{32}$ las ediciones más recientes de las obras de La Palma, que fueron publicadas respectivamente en 1961 y 1967. Por orden cronológico, los escritos más importantes de La Palma son ${ }^{33}$ :

- Historia de la Sagrada Pasión ${ }^{34}$ (1624): el primero de sus grandes escritos y el más conocido. Se ha reeditado infinidad de veces y se ha traducido a seis lenguas extranjeras.

22 Cf. Rodríguez Molero, “Palma, Luis de la”, en DHCJ, vol. III, 2960-2961.

23 Cf. Alonso Andrade, Varones ilustres en santidad, letras y zelo de las almas, vol. V (Madrid, 1666), 592.

24 Cf. Feliciano Cereceda, "Carta necrológica sobre el P. Luis de La Palma", Manresa 63 (1945): 155.

25 Cf. Celestino Testore, s.v. "La Palma (Luis de)", en Enciclopedia Cattolica, ed. Giuseppe Pizzardo, Pio Paschini, y Celestino Testore, vol. VII (Roma: Città del Vaticano, 1951), 905.

26 Cf. Pedro Leturia, Estudios ignacianos (Roma: IHSI, 1957) 2:4-5.

27 Cf. Robert Ricard, "San Juan de Ávila, inspirador del P. La Palma", Revista de Occidente XLIX (1975): 198.

28 Cf. Santiago Arzubialde, Ejercicios Espirituales de San Ignacio. Historia y análisis, 2. ${ }^{\mathrm{a}}$ ed. (Bilbao: M-ST, 2009), 80.232.234.368.394.408.411.413.558.579.872.

29 Cf. Astrain, 5:96.

30 Rodríguez Molero, “Introducción”, en Luis de La Palma, Obras (Madrid: BAC, 1967), 21.

31 Cf. Luis de La Palma, Obras Completas, ed. Camilo Abad, vol. 144, 145 y 160 (Madrid: Biblioteca de Autores Españoles, 1961-1963).

32 Cf. Id., Obras, ed. Rodríguez Molero (Madrid: BAC, 1967). En adelante, utilizamos esta edición de Rodríguez Molero cada vez que ofrecemos la numeración de las páginas de los textos de La Palma.

33 Cf. Carlos Sommervogel, Bibliothèque de la Compagnie de Jésus (Bruxelles, 1895), 6:150-155.

34 La Palma, 65-330.

ESTUDIOS ECLESIÁSTICOS, vol. 94, núm. 368, marzo 2019, 75-116, ISSN 0210-1610, ISSN-e 2605-5147 
- Camino Espiritual ${ }^{35}$ (1626): la obra más relevante, que escribió en Madrid después de su rectorado en Alcalá para explicar los Ejercicios de san Ignacio. Su deseo inicial fue que tuviera tres partes, pero solo pudo terminar la primera por falta de salud y otros ministerios que le encargaron.

- Práctica y breve declaración del camino espiritual ${ }^{36}$ (1629): un comentario de las meditaciones de Ejercicios de apenas 8 días completos.

Aunque de importancia menor, son también interesantes estos otros escritos: Tratado del Examen general de la conciencia ${ }^{37}$ y Tratado sobre el Examen particular de la conciencia ${ }^{38}$ (publicados en 1700 y 1704, respectivamente), Del uso y abuso de la Sagrada Comunión ${ }^{39}$ y Meditaciones de la Virgen Nuestra Señora ${ }^{40}$.

No cabe duda de que su obra Camino Espiritual es de los comentarios a los Ejercicios de san Ignacio más clásicos y logrados. Para Iparraguirre y Luis González, que hablan de La Palma en 37 ocasiones $^{41}$, apenas unos pocos comentarios a Ejercicios pueden denominarse clásicos:

«Los actuales comentarios de los Ejercicios se basan en un número muy reducido de autores: Gagliardi, La Palma, Suárez, Diertins, Le Gaudier, Roothaan, Denis y pocos más. Los demás han quedado sepultados en el olvido» ${ }^{42}$.

Podemos encontrar en la obra Camino Espiritual de La Palma un incipiente tratado de Teología Espiritual, una sistematización del carisma ignaciano. Sorprende, por este motivo, que apenas haya sido publicado en seis ocasiones a lo largo de estos siglos: en 1626, en Alcalá de Henares; en 1860 y 1887, en Barcelona; una traducción latina en 1887; y las dos ediciones más recientes de sus obras que hemos citado.

\footnotetext{
35 Ibid., 422-836.

36 Ibid., 839-921.

37 Cf. La Palma, Obras Completas, ed. Camilo Abad, 160:9-92.

38 Cf. Ibid., 93-161.

39 Cf. Ibid., 175-194.

40 Cf. Ibid., 231-247.

41 Cf. Luis González e Ignacio Iparraguirre, Ejercicios Espirituales. Comentario pastoral (Madrid: BAC, 1965).

42 Ibid., 130.
} 


\subsection{La voluntad de Dios en «Camino Espiritual»}

En conformidad con el planteamiento tomista, La Palma presenta la voluntad de Dios como voluntad de beneplácito y voluntad significada ${ }^{43}$.

La voluntad de beneplácito de Dios es el designio divino que es preciso acatar ${ }^{44}$ : Cristo vive sometido a la voluntad del Padre como se ve, por ejemplo, en Getsemanít5. Lo que el Padre pide con respecto a esta voluntad suya como designio divino es conformidad pasiva, aceptación ${ }^{46}$.

La voluntad significada de Dios se manifiesta comúnmente por la revelación a la humanidad de la ley moral y sus mandamientos, y por la prescripción de huir del mal y buscar el bien. Lo que Dios pide, en este caso, es obediencia y conformidad activa a sus leyes: aborrecer el peca$\mathrm{do}^{47}$, huir de las ocasiones de pecado ${ }^{48}$, el temor de Dios ${ }^{49}$ y la práctica de las virtudes ${ }^{50}$.

Asimismo, cabe hablar de una voluntad significada de Dios como expresión de los deseos que Dios comunica a sus amigos ${ }^{51}$. Dios invita con respecto a esta acepción a buscar su agrado, acoger sus anhelos en la contemplación y cumplirlos con amor ${ }^{52}$.

Omitimos ahora la primera de las comprensiones del término (voluntad de beneplácito) para centrarnos en la voluntad significada y los dos

43 San José María Rubio sintetizó la conformidad con la voluntad de Dios de beneplácito y significada, con una máxima que se ha hecho célebre: «Querer lo que Dios hace y hacer lo que Dios quiere» (cf. Carlos Fernández Barberá, La fuente que mana y corre. Cincuenta testigos fascinantes (Madrid: Narcea Ediciones, 2000), 64).

44 Cf. La Palma, 141.252.256.271.284.

45 Ibid., 145: «Dijo, pues, el Señor: Padre, Padre, y Padre singularmente mío, que soy tu Hijo natural: Si es posible, o, como dijo otro evangelista: Si Tú quieres, esto es, si con tu voluntad y queriéndolo Tú es posible, suplícote que no beba Yo este cáliz. Como si dijera: Yo no quiero cosa que Tú no quieras; lo que Tú no quieres, eso, aunque sea por sí mismo muy fácil, es para Mí como imposible; y, por tanto, Señor, lo que te pido es con condición que tú lo quieras [...]».

46 Ibid., 257: «¿[...] qué agradamiento tendría el Eterno Padre con la vista de aquel tan amado y obediente Hijo, viéndole tan bien puesto en la cruz, sin rastro de impaciencia o de flaqueza, padeciendo con tanta mansedumbre y ofreciéndose con tanta caridad $[\ldots] »$.

47 Cf. Ibid., 465-471.

48 Cf. Ibid., 480-483.

49 Cf. Ibid., 483-486.

50 Cf. Ibid., 518-525.

51 Cf. Ibid., 614.667.

52 Cf. Ibid., 603.646. 
significados que puede revestir en los escritos del P. La Palma. Entre estas dos formas de entender la voluntad significada de Dios hay un matiz interesante, que es en el que ahora centramos nuestro interés ${ }^{53}$.

- Hay pasajes en los que no está claro si La Palma quiere expresar que la voluntad de Dios es un deber prescrito o un mero deseo de Dios, porque utiliza palabras que, a priori, parecen neutrales, como son voluntad de Dios o voluntad divina, es decir, que podrían interpretarse como mandatos (un deber que debemos cumplir) o como anhelo de Dios (un deseo que nos solicita) ${ }^{54}$.

- Hay ocasiones en las que el autor emplea términos que, sin lugar a dudas, hacen referencia a la voluntad de Dios como mandato que se impone: preceptos, normas, mandamientos, leyes. Es una comprensión de la voluntad de Dios que podemos denominar deontotónica, la cual subraya el deber que el ser humano tiene de cumplir determinadas obligaciones con respecto a Dios ${ }^{55}$.

- Y otras veces usa términos que, sin duda alguna, hacen referencia a la voluntad de Dios como deseo que Dios muestra de lo que le agrada o complace, de lo que le gusta, de su beneplácito. Es una comprensión de la voluntad de Dios agapetónica, en tanto que subraya la relación interpersonal y afectiva entre el hombre y $\operatorname{Dios}^{56}$.

Es este último significado en el que podemos encuadrar lo que a menudo puede sentir y hallar quien vive la experiencia de los ejercicios de san Ignacio, y a este significado dedica el P. La Palma algunas páginas muy sugestivas que hemos citado, con expresiones propias de un amigo en el Señor.

53 Sigo en esta caracterización los hagionormos (tipos de santidad) propuestos por Alejandro Roldán en: Alejandro Roldán Viller, Introducción a la ascética diferencial (Madrid: Razón y Fe, 1968). Roldán, a su vez, se sirve de la tipología de Sheldon, descrita en: William Herbert Sheldon, Las variedades del temperamento: psicología de las diferencias constitucionales (Buenos Aires: Paidos, 1972).

${ }_{54}$ Cf. La Palma, 431-432.440-443.450-452.455-457.463-465.550-554.563-567.596599.603-611.616-618.652-659.667-670.682-686.

55 Cf. Ibid., 440-443.445-447.450-457.459-462.467-473.477-483.486-492.513516.521-525.527-531.537-540.550-554.563-567.583-587.594-599.616-618.629652.656-663.670-686.

56 Cf. Ibid, 443-445.452-455.492-494.498-503.576-578.607-611.614-616.636-643. 652-663.670-673.682-686. 
Esta forma de comprender la voluntad de Dios no es exclusiva del P. La Palma ni de la tradición espiritual ignaciana, sino que ha sido presentada por otros autores espirituales. Los autores que se han distinguido por esta forma de comprender «lo que Dios quiere» son precisamente los que han subrayado con mayor intensidad el misterio de la humanidad de Cristo $^{57}$ como puerta de acceso del hombre a Dios: san Pablo, los autores franciscanos, la Devotio Moderna y, fundamentalmente, como pronto veremos, san Ignacio de Loyola, un místico dedicado al apostolado, un contemplativo en acción.

\subsection{ANÁLISIS DEL TEXTO}

2.3.1. Análisis semántico del texto de los libros I-III, dedicados a las tres vías

Hemos analizado el texto de Camino Espiritual rastreando las alusiones que hace a la voluntad de Dios, procurando distinguir en qué partes de la obra utiliza unas u otras expresiones para referirse a este concepto. Para este análisis hemos distinguido los tres grupos de términos a los que hicimos alusión, con los cuales identifica La Palma la voluntad de Dios, y que incluimos en este cuadro:

\begin{tabular}{lccc}
\hline & Neutral & Deontotónico & Agapetónico \\
\hline & $\begin{array}{c}\text { Voluntad de } \\
\text { Dios, voluntad } \\
\text { divina }\end{array}$ & $\begin{array}{c}\text { Mandatos, manda- } \\
\text { mientos, preceptos, } \\
\text { obligaciones, ley }\end{array}$ & $\begin{array}{c}\text { Agrado, } \\
\text { beneplácito, } \\
\text { complacencia }\end{array}$ \\
\hline $\begin{array}{l}\text { LIBRO I } \\
\text { (vía purgativa) }\end{array}$ & 8 & 21 & 4 \\
\hline $\begin{array}{l}\text { LIBRO II } \\
\text { (vía iluminativa) }\end{array}$ & 3 & 29 & 1 \\
\hline $\begin{array}{l}\text { LIBRO III } \\
\text { (vía unitiva) }\end{array}$ & 12 & 28 & 18 \\
\hline
\end{tabular}

Podemos hacer varias observaciones sobre este análisis textual ${ }^{58}$ :

57 Cf. Ricardo García-Villoslada, "Rasgos característicos de la «Devotio Moderna»", Manresa 108 (1956): 317.

58 Nota: Omitimos el resultado en los capítulos IV y V porque, referidos no al progreso del ejercitante sino a aspectos más técnicos de los ejercicios, no aportan resultados relevantes. 
a. Para Luis de La Palma la voluntad de Dios no se manifiesta igual a los que están en la vía purgativa, iluminativa o unitiva: mientras que los términos deontotónicos se mantienen en esas tres vías, las alusiones agapetónicas se multiplican en la vía unitiva.

b. Es proporcional el uso que hace de conceptos agapetónicos al uso que hace de términos neutrales, que no especifican un sentido u otro (columnas $1 .^{\mathrm{a}}$ y $3 .^{\mathrm{a}}$ ). Por el contrario, no se sigue proporción alguna entre el uso que hace de términos deontotónicos y el uso del término neutral (columnas 2. ${ }^{\mathrm{a}}$ y $3{ }^{\mathrm{a}}$ ). Es decir, que el autor habla tanto de voluntad de Dios cuanto habla de agrado, gusto, complacencia o beneplácito de Dios: tanto en sentido neutral como en sentido agapetónico.

c. A mi modo de ver esto sugiere que, para el autor, la aparentemente neutral expresión voluntad de Dios no significa primordialmente mandato de Dios sino agrado de Dios.

d. El número de ocasiones en que utiliza esta expresión en el Libro III, que aborda la vía unitiva (18 veces), es muy desproporcionado a las veces que lo utiliza en el resto de los libros (5): más del triple de la suma de la aparición de este término en los otros libros. Esto quiere decir que cumplir en profundidad la voluntad de Dios, entendida como buscar el agrado de Dios, no es tarea de incipientes sino de quienes han llegado a una unión estrecha, a una gran sintonía interior con el Señor.

e. Esto no quiere decir que el seguimiento de Cristo y el cumplimiento de su voluntad sean ajenos al cumplimiento de sus mandamientos y leyes: «Si me amáis, guardaréis mis palabras» (Jn 14,15); "vosotros sois mis amigos si hacéis lo que yo os mando» (Jn 15,14). Los términos deontotónicos, como puede advertirse en la columna $2 .^{a}$, son numerosos en todas las partes del libro, es decir, tienen aplicación en todas las etapas de la vida espiritual. Pero esto significa que el seguimiento de Cristo no es solo cumplir mandamientos, sino que el hombre está invitado a una intimidad con el Señor mucho mayor, más profunda, a una relación interpersonal de amistad. En la vía unitiva, si sumamos las columnas $1 .^{\mathrm{a}}$ y $3 .^{\mathrm{a}}$, se advierte que son más numerosas que la columna $2 .^{\mathrm{a}}$, lo cual quiere decir que las alusiones a la voluntad de Dios desde una perspectiva agapetónica prevalecen sobre las que tienen una perspectiva deontotónica. 


\subsubsection{Capítulos más significativos}

Como hemos expuesto en el cuadro anterior, hemos procurado examinar de forma minuciosa todas las veces que aparecen referencias a la voluntad divina en cada uno de los libros que componen la obra Camino Espiritual, y también hemos identificado si estas alusiones se hacen con términos de significado neutro (N), deontotónico (D) o agapetónico (A).

Ahora podemos subrayar un detalle importante de esta investigación que nos permite profundizar en el contexto, el significado y la repercusión que el empleo de estos conceptos entraña: el Libro III, dedicado a la vía unitiva, es el libro que ofrece un tratamiento más extenso de la cuestión de la voluntad divina en términos afectivos. Y, en el interior de ese libro, los capítulos 17-19 (que son los capítulos en los que trata los últimos grados de la vía unitiva), son los capítulos en los que más claramente se ofrece esta perspectiva de la voluntad divina.

$\mathrm{El}$ autor hace referencia al cumplimiento de la voluntad divina al explicar que en la vía unitiva es posible vivir como contemplativos en acción (grado $3 .^{\circ}$ de la vía unitiva), reducir a Dios todas las perfecciones $\left(4 .^{\circ}\right)$ y perseverar con ánimo varonil $\left(5^{\circ}\right)$. Esto quiere decir que para el P. La Palma cumplir la voluntad divina, comprendida como agrado de Dios y su mayor complacencia, es lo propio de las almas que han llegado a la perfección, a la cumbre de la unión con Dios.

\subsubsection{Párrafos escogidos}

Por su interés incluimos aquí las ocasiones más significativas en las que habla de agradar a Dios el Libro III, dedicado a la vía unitiva. Para evitar repeticiones, hemos escogido 5 expresiones de las 18 alusiones $^{59}$ que incluye el autor:

- C. XVII. 7: «Síguese el tercer grado, que es poner por obra lo que es del gusto y beneplácito divino ${ }^{60}$.

59 Cf. La Palma, 444.456.498.560.575.602.609.643.652.656.658.659(2).660.671. 683.690.703.787.

60 La Palma, 652. El subrayado de los términos agapetónicos es nuestro, tanto en este fragmento como en los siguientes. 
- C. XVIII. 9: «Indicio es de haber llegado a este grado, cuando de mis obras y ocupaciones no quiero otro fruto más que haber agradado a la divina Majestad» ${ }^{61}$.

- C. XVIII. 10: «[...] no deseo otro efecto ni otro suceso, ni miro, ni reparo, ni examino otra cosa en ellas, sino ésta tan solamente: si han salido y se han hecho a gusto de Dios»"22.

- C. XVIII. 11: "[...] no halla qué amar ni a quién agradar fuera de Dios; pues todo lo que hay en las criaturas, lo halla con infinitas ventajas en Dios» ${ }^{63}$.

- C. XVIII. 12: «Cerrando los ojos a los fines particulares, su fin ha de ser solamente glorificar y agradar a la divina Majestad» ${ }^{64}$.

Con este simple botón de muestra podemos ver que, para el P. La Palma, la unión del alma con Dios entraña una sintonía de voluntades entre ambos, averiguar y cumplir lo que agrada al Señor, salir de uno mismo, y es la cumbre de la vida espiritual. Buscar el agrado de Dios es un ejercicio de perfectos, y por eso el autor lo explica al referirse a los grados de perfección a los que está llamada el alma en la vía unitiva.

Después de haber enunciado un breve resumen de pasajes en los que trata del agrado de Dios el Libro III, y de haber ofrecido una explicación somera de ellos, profundizamos ahora en el significado que la voluntad divina tiene para el autor.

\subsubsection{Conceptos utilizados, raíz etimológica y campos semánticos}

Entre todas las expresiones que denominamos agapetónicas, de las cuales se sirve el P. La Palma para referirse a la voluntad de Dios, las más recurrentes en los capítulos I-III son las siguientes: agrado-agradar (13 veces), dar gusto a Dios (8), complacer-complacencia (2). Profundizamos, por este motivo, en el significado de la expresión agrado-agradar y en su etimología:

- «Agradar»: el conocido diccionario de Sebastián de Covarrubias del año 1611 define esta expresión como «contentar, dar

\footnotetext{
61 Ibid.

62 Ibid.

63 Ibid., 658.

64 Ibid., 658-659.
} 
contento ${ }^{65}$. Los diccionarios de siglos posteriores no modifican esta definición: "complacer, contentar» ${ }^{66}$.

- «Agrado»: «afabilidad ó agasajo que se manifiesta en el trato, en el semblante y otras demostraciones. Voluntad ó gusto, y así se dice al rey en las consultas: V. M. resolverá lo que sea de su agrado» ${ }^{67}$.

La etimología de ambos términos es común: proceden del castellano antiguo "grado» ${ }^{68}$, cuyo significado es doble: por un lado, "cada uno de los diversos estados o niveles que, en relación de menor a mayor, puede tener algo»; y, por otro lado, "voluntad, gusto» ${ }^{69}$. El motivo de que la voz "grado» sea una palabra polisémica es sencillo. El término «grado» en castellano procede de dos raíces latinas ${ }^{70}$, de las cuales recibe sus significados: del latín gradus, que significa «grada, escalón»; y del latín gratus, que significa "voluntad, gusto». En este segundo sentido evoluciona hacia dos palabras admitidas en castellano: grado y grato.

Por consiguiente, «voluntad de Dios» y «agrado de Dios» son dos conceptos que en latín pueden expresarse con el mismo término gratus (aunque el latín prefiere el uso de voluntas al de gratus para referirse a la voluntad), pero en todo caso es claro que el castellano distingue estos dos conceptos con palabras diferentes. Para comprender la diferencia que tienen en el castellano los términos «voluntad» $\mathrm{y}$ «agrado» es útil poner cada una de estas expresiones en relación con su campo semántico, como hacen los Diccionarios ideológicos ${ }^{71}$.

65 Cf. Sebastián de Covarrubias, ed., Tesoro de la lengua castellana o española (La Coruña: Orbigo, 2013).

66 Cf. "Agradar", en Diccionario General etimológico de la Lengua Española, dir. Roque Barcia y Eduardo de Echegaray (Madrid, 1887), 1:146. Del mismo modo lo define el Diccionario de la Lengua Española. El término «agradar» no figura en el célebre Diccionario crítico etimológico castellano hispánico, dir. Joan Corominas y José Antonio Pascual (Madrid: Gredos, 1984-1987).

67 Ibid.

68 Cf. "Grado", en Diccionario General etimológico, 3:66.

69 Ibid.

70 Ibid.: «1. grado: catalán antiguo, agradatge; moderno, agrado; francés, agrément. 2. Del latín ad, á, y gratus, grato».

71 Para esta cuestión seguimos la obra: Diccionario de ideas afines, ed. Eduardo Benot, 5 vol. (Madrid: Mariano Núñez Samper, 1899).

El campo semántico del término «voluntad» tiene asociados varios conceptos que enfatizan el aspecto de determinación consciente y libre: deseo, querer, ganas, firme, anhelo, ansia, afán, empeño, ambición, aspiración, iniciativa, intento, intención, propósito, determinación, resolución, decisión, volición, motu proprio. 
Cabría preguntarse por qué si en castellano no se identifica la palabra «voluntad» con la palabra «agrado», el P. Luis de la Palma parece utilizar la primera como sinónimo de la segunda. A mi entender, la respuesta que podemos ofrecer a esta pregunta no es de carácter filológico, sino vital: la experiencia y relación del autor con Cristo vivo, de quien fue compañero y amigo, le abrió a una comprensión del cumplimiento de la voluntad divina que no se redujo a la de mero ejecutor de sus instrucciones, sino la del amigo que colabora gustoso con su amigo.

\subsubsection{La voluntad de Dios como agrado de Dios}

Esta cuestión es la más relevante con respecto a la explicación que ofrece La Palma de la voluntad de Dios.

La Palma sigue en su obra Camino Espiritual el esquema de las tres vías o tres estados de la vida espiritual ${ }^{72}$ (esquema discutible, por otra parte, y que autores como Arzubialde ${ }^{73}$ consideran que no es el genuino de san Ignacio en los Ejercicios). En todo caso, desde la perspectiva del P. La Palma:

- La vía purgativa ${ }^{74}$ persigue eliminar el pecado, las pasiones y los afectos desordenados ${ }^{75}$. Para alcanzar este objetivo, es necesario cumplir los mandamientos y aceptar las circunstancias vitales tal como Dios las permite, esto es, admitir lo que Dios hace.

- El objetivo de la vía iluminativa ${ }^{76}$ es la imitación de Cristo ${ }^{77}$ y el crecimiento en la virtud ${ }^{78}$. Y por esta razón es necesaria la medi-

«Agradar» no figura con un campo semántico propio, sino que pertenece al campo semántico del término «deleite», al cual pertenecen otros términos que aluden a la dimensión afectiva: agrado, gratitud, alegría, atractivo, atracción, encanto, fascinación, imán, gancho, seducción, amabilidad, dulzura, ternura, mimo, halago, lisonja, cariño, amor, belleza, hermosura, buen trato, beldad, palabras dulces, melosidad, gracejo, bondad, regalo, comodidad, etc. Con el verbo deleitar: agradar, agradecer, hacer gracia, gratificar, alegrar, divertir, dar gusto, ser motivo de alegría, causar placer, atraer, encantar, fascinar, electrizar, magnetizar, seducir, enganchar, ser amable, gustoso, deleitoso, dulcificar, endulzar, aliviar, mimar, halagar, lisonjear.

72 Cf. Ibid., 447-448.457-459.

73 Cf. Arzubialde, 80.

74 Cf. Rodríguez Molero, “Introducción”, en La Palma, 370-381.

75 Cf. La Palma, 126.453.462.486.463.465-467.477.480.483.487.488-508.

76 Cf. Rodríguez Molero, "Introducción”, en La Palma, 382-397.

77 Cf. La Palma, 527-534.

78 Cf. Ibid., 510.518-589. 
tación de los misterios de la vida de Cristo, en los que encontramos el modelo a imitar. La voluntad de Dios en esta segunda vía consiste en ajustar la propia vida a los preceptos y mandamientos divinos y en imitar las virtudes de Cristo. Ninguno de estos dos pasos -querer lo que Dios hace, y cumplir los mandamientos- requiere una amistad estrecha con Jesucristo. Esto no significa que no sea precisa la gracia divina para superar los vicios y malas inclinaciones, pero es cierto que la formación intelectual recibida puede dar elementos suficientes para comprender el horizonte de virtud hacia el que se debe caminar, los pecados que se deben evitar y las acciones buenas que -con la ayuda de la gracia- se deben procurar realizar.

- El camino, que culmina en la vía unitiva ${ }^{79}$, lleva al alma a la amistad estrecha con Jesucristo, a la plena unión de voluntades, a la conformación del corazón a imagen del de Cristo ${ }^{80}$. La vía unitiva lleva a ser uno con el Señor, a salir de sí mismo para vivir en Dios. En este contexto resulta muy iluminador el planteamiento de la voluntad de Dios que hace el P. La Palma en la etapa cumbre de la vida espiritual ${ }^{81}$ : las palabras que denotaban una sumisión al mandato inexorable de Dios dejan paso a otros conceptos distintos, como son agradar, conocer mejor su gusto, complacer.

Lo afirmado hasta aquí no significa que en este estado de la vida espiritual no sea necesario cumplir los mandamientos o aceptar los designios de Dios en su providencia, pero aquello resulta ya insuficiente: el alma ha sido invitada a una intimidad con el Señor en la que ese cumplimiento formal de los mandamientos se da ordinariamente, y surge con naturalidad de un corazón transformado a imagen del Corazón del Señor.

Es el sentido de las expresiones de san Pablo: «para el justo no hay ley» (Rom 2,14), y «la ley no fue dada para el justo, sino para los transgresores» (1Tim 1,9). Ambas no significan que la ley pueda ser transgredida, sino que al justo no es necesario imponerle esta ley, porque cumplir la ley de Dios brota espontáneamente de su corazón justo, acata con gusto esta ley.

\footnotetext{
79 Cf. Rodríguez Molero, “Introducción”, en La Palma, 397-403.

80 Cf. La Palma, 607-616.

81 Cf. Ibid., 652-659.
} 
El P. La Palma explica este itinerario interior de la vida espiritual como una amistad con Jesucristo ${ }^{82}$ que culmina en la unión:

«De dos notas ó advertencias que puso nuestro santo Padre por fundamento del ejercicio del amor, hemos declarado hasta aquí la primera, conviene a saber: Que el amor se ha de poner más en las obras que en las palabras; resta declarar la segunda: Que el amor consiste en comunicación de las dos partes [...]. Esta doctrina parece dificultosa, no solamente de entenderse, pero mucho más de practicarse, si es así que ha de trabar amistad el hombre con Dios, y la criatura con su Criador» ${ }^{83}$.

La amistad es una relación libre de entrega personal recíproca. Para llegar a esa confianza de los amigos, es necesario previamente haber sido introducido en la presencia de Dios, respetar su grandeza, reconciliarse con Él:

«Porque ¿cómo puede el pecador tratar de unión con Dios, si no hace primero amistades con él? y ¿cómo puede tratar de salvación sin salir primero del estado de condenación? ¿Ni tratar de premio el que es deudor de pena eterna?» ${ }^{84}$.

Pero esta purificación previa del alma, que es precisa para entrar en la amistad y unión con el Señor, no es el objetivo o el horizonte final de la vida espiritual para La Palma. Por el contrario, presenta como meta la unión plena y definitiva, la contemplación y vida mística:

«[...] el que ama está dentro de su amigo, porque le mira como á sí mismo, y sus males y bienes como si fueran suyos. Y como la amistad hace retorno en esto entre los amigos, así se miran los dos el uno al otro como si fueran uno mismo. Esto es lo que enseña santo Tomás. De todo lo cual se saca, que la unión que la caridad perfecta hace en esta vida, consiste en un conocimiento claro, quieto y profundo de Dios y de sus misterios, que causa deleite y admiración; el cual solemos llamar contemplación $[\ldots]]^{85}$.

\footnotetext{
82 Cf. Ibid., 107.

83 Ibid., 643.

84 Ibid., 465.

85 Ibid., 614.
} 


\subsubsection{Actualidad de la doctrina de La Palma sobre la voluntad de Dios}

Una consecuencia interesante de la perspectiva de La Palma que hemos descrito es que permite comprender mejor la relación personal y única que el Señor desea establecer con cada individuo. La voluntad de Dios es insinuación particular de Dios para cada uno. Hay, en este sentido, una voluntad de Dios para cada persona, lo cual explica que -en la escuela de san Ignacio- se insista en que el que da los ejercicios no debe influir en la elección ${ }^{86}$, porque lo que se propone al ejercitante no es solo conocer la ley universal de Dios, sino un diálogo personal de amistad entre el ejercitante y el Señor, en el curso del cual el Señor irá mostrando su agrado.

La vida cristiana, concebida de esta manera, no es un camino que «uniformice» a los creyentes, que disuelva la diversidad en aras de una unidad de la fe. Por el contrario, el Señor (aunque, ciertamente, ha propuesto mandamientos universales) ofrece después a cada persona un itinerario específico y único. La intervención del que da los ejercicios podrá servir de instrumento para ayudar al ejercitante a ir captando las invitaciones del Señor, pero en ningún caso el que da los ejercicios puede sustituir al Señor, que es verdadero interlocutor del diálogo directo con el ejercitante ${ }^{87}$.

Esta clave de comprensión de la vida cristiana como encuentro y amistad personal tiene una enorme importancia en la actualidad. En pleno siglo XXI, el cristianismo corre el mismo riesgo que en el siglo XVI: convertirse, como García-Villoslada atribuye a Erasmo de Rotterdam, en «una escuela de moral» ${ }^{88}$, perdiendo así la riqueza de una amistad real y gozosa con Cristo vivo y resucitado:

«No se comienza a ser cristiano por una decisión ética o una gran idea, sino por el encuentro con un acontecimiento, con una Persona,

86 Cf. Ej. 15. También los Directorios para la aplicación de los ejercicios insisten en que el que imparte los ejercicios no debe persuadir ni mover la voluntad del ejercitante en un sentido ni en otro. A continuación, las citas de dichos Directorios según la ordenación establecida por Lop, en Miguel Lop Sebastià, ed., Los Directorios de Ejercicios 1540-1599 (Bilbao: M-ST, 2000): D4 (8-9), D20 (84), D21 (10), D22, 23 (83), D31 (115-116), D32 (127), D33-34-43 (174), D46 (49-53), D47 (20-25).

87 Karl Rahner, Palabras de Ignacio de Loyola a un jesuita de hoy (Santander: Sal Terrae, 1990), 6-8.

88 Ricardo García-Villoslada, "San Ignacio de Loyola y Erasmo de Rotterdam”, Estudios Eclesiásticos 16 (1942): 236. 
que da un nuevo horizonte a la vida y, con ello, una orientación decisiva» ${ }^{89}$.

La actualidad de esta cuestión no termina aquí. La comprensión de la voluntad de Dios como agrado del Señor abre nuevas perspectivas en otros ámbitos de la reflexión teológica. Por ejemplo, nos parece iluminador para el debate sobre el objetivo que pretende la experiencia de los ejercicios. Se han ofrecido, fundamentalmente, dos respuestas a la pregunta sobre cuál es el fin último de los Ejercicios.

Para algunos autores, como Karl Rahner, el objetivo de los ejercicios es el proceso de elección, es decir, ayudar al ejercitante a que se ponga en disposición de buscar y hallar la voluntad de Dios, sin verse condicionado por sus afecciones desordenadas: «El factor determinante de los ejercicios ignacianos es la elección personal, que cabrá abordar de muy diversas maneras $[\ldots] »^{90}$. Para otros autores como Peeters ${ }^{91}$, por el contrario, los ejercicios buscan la unión con Dios más íntima y total, llegar a la cumbre de la mística.

Pues bien, una vez comprendido que cumplir la voluntad de Dios consiste en agradar a Cristo sumamente amado, es más sencillo convenir que las finalidades propuestas para los ejercicios no son excluyentes, sino que prácticamente convergen y se pueden identificar. Desde esta perspectiva, se llega a la unión total por la unión de voluntades, es decir, por elegir lo que agrada más al Señor; y la elección perfecta es la que nace de una amistad profunda y de una entrega plena de amor a Jesucristo.

Veamos ahora de dónde pudo llegar a La Palma esta manera de comprender la voluntad de Dios. Omitimos las fuentes anteriores a san Ignacio, que harían prolijo este elenco ${ }^{92}$, para centrarnos en las influencias más inmediatas que pudieron llegar al P. La Palma, las de los primeros compañeros de san Ignacio, y las de otros autores jesuitas coetáneos a nuestro autor.

\footnotetext{
89 Benedicto XVI, Carta encíclica Deus caritas est, n. 1, en AAS 98 (2006), 217.

90 Karl Rahner, Meditaciones sobre los Ejercicios de san Ignacio (Barcelona: Herder, 1971), 17.

91 Cf. Luis Peeters, Hacia la unión con Dios por medio de los Ejercicios de S. Ignacio (Bilbao: Mensajero, 1944), 47-67.

92 Sobre el origen etimológico del término "voluntad», sobre la comprensión teológica de este concepto en la Escritura, Santos Padres, y autores espirituales anteriores a san Ignacio, cf. Manuel Vargas Cano de Santayana, "La Anotación 15. ' de los Ejercicios Espirituales de san Ignacio de Loyola" (Facultad de Teología, Universidad Pontificia Comillas: Madrid, 2017), 137-160.
} 


\section{OTROS AUTORES QUE COMPARTEN LA PERSPECTIVA DE «VO- LUNTAD DE DIOS» COMO «AGRADO DE DIOS»}

No es sencillo poner en relación la comprensión de la voluntad divina en la obra del P. La Palma con otros autores. Esto requeriría un estudio profundo de la teología que subyace a cada uno de estos autores, que fueron prolíficos -en algún caso- y heterogéneos en la forma que adoptaron para sus escritos (cartas, libros de meditaciones, apuntes personales, etc.). Lo que nos proponemos es descubrir cómo el campo semántico utilizado por el P. La Palma para referirse a la voluntad de Dios es compartido por varios autores, con una sencilla muestra de párrafos extraídos de sus obras, lo cual puede llevarnos a algunas conclusiones interesantes.

\subsection{LOS PRIMEROS JESUITAS}

La importancia de los primeros compañeros es decisiva para la Compañía de Jesús. El estilo espiritual que compartieron, en líneas generales, fue el modelo para las generaciones sucesivas. En particular, el trato que cada uno de estos fundadores tuvo con Íñigo de Loyola, y la experiencia de los ejercicios que hicieron gracias a él, configuró de tal modo su modo de ser y de vivir que podríamos decir que el Señor «troqueló» sus personalidades con este molde espiritual.

\subsubsection{San Ignacio de Loyola (1491-1556)}

\section{a. Voluntad para san Ignacio}

La palabra voluntad ${ }^{93}$ responde para san Ignacio al uso moderno: la determinación para actuar, querer ${ }^{94}$. Es heredero de la antropología de la Devotio Moderna, que recibe en Montserrat y Manresa, quizá a través del Exercitatorio de Cisneros ${ }^{95}$, quien había sido abad del monasterio.

\footnotetext{
93 Cf. Dominique Salin, "Voluntad", en DEI, vol. II (Bilbao: M-ST, 2007), 17871790.

94 Cf. "Voluntad", en Ignacio Echarte, ed., Concordancia Ignaciana (Bilbao: M-ST, 1996), 1347-1349.

95 Edición más reciente en: Francisco García de Cisneros, Ejercitatorio de la vida espiritual (Madrid: Rialp, 1957).
} 
Esta antropología, que se remonta a san Agustín (De Trinitate $\mathrm{X}^{96}$ ) entiende que memoria, inteligencia y voluntad constituyen las tres potencias o facultades del alma.

San Ignacio recibe, además, en París, directamente la influencia de la mística flamenca. Comprende la voluntad como capacidad de estar afectado y asiento de los afectos. Antes de ser capacidad de querer, la voluntad es capacidad de afectarse, de experimentar los afectos (affectus y affectio en latín, que san Ignacio traduce por afecto y afección o afecciones): la voluntad es el asiento de los afectos. San Agustín había ya asociado la voluntas con el afecto mayor que es el amor, y había priorizado la voluntad sobre el entendimiento. La tradición medieval (por ejemplo, san Bernardo ${ }^{97}$ y san Buenaventura ${ }^{98}$ ) también había valorado la importancia de los afectos.

b. Comprensión ignaciana de la voluntad de Dios

Abordaremos esta cuestión desde dos perspectivas complementarias: cómo fue descubriendo Ignacio la voluntad de Dios para su propia vida; y, posteriormente, cómo explicó a otras personas el modo de hallar la voluntad divina (la experiencia personal de búsqueda de la voluntad de Dios, y el magisterio que nos ha legado sobre esta cuestión).

c. La voluntad de Dios en la vida de san Ignacio

Dios no manifestó su voluntad a Ignacio íntegramente desde el principio, sino que le permitió ir conociendo su voluntad paulatina y progresivamente $^{99}$. Tuvo que peregrinar ${ }^{100}$ por los caminos de Europa y preguntar al Señor qué quería de él. En este sentido, puede decirse que,

96 Cf. San Agustín, Tratado sobre la Santísima Trinidad (Madrid: BAC, 1956), 605-609.

97 Cf. San Bernardo de Claraval, Sermones sobre el Cantar de los Cantares, ed. José Luis Santos Gómez (Madrid: Alpuerto, 2000).

98 Cf. San Buenaventura, "Itinerario de la mente a Dios", en Obras, ed. León Amorós, Bernardo Aperribay, Miguel Oromi, y León Villuendas Polo (Madrid: BAC, 1968), 1:543-636.

99 Cf. Ruiz Jurado, El peregrino de la voluntad de Dios. Biografía espiritual de San Ignacio de Loyola (Madrid: BAC, 2005), 78-79. 106.

100 Sobre la importancia para la espiritualidad ignaciana de los términos peregrino, peregrinación, camino..., cf. Francisco José Ruiz Pérez, "Camino”, en DEI, $1: 260-267$. 
además de su trayectoria geográfica, vivió también una "peregrinación espiritual» ${ }^{101}$. El Señor le mostró su voluntad de varias formas:

- Con ilustraciones, como en el Cardoner ${ }^{102}$ y en la Storta ${ }^{103}$.

- Con acontecimientos que le sucedieron, como la expulsión de Tierra Santa ${ }^{104}$.

- Otras veces fue él quien tomó las determinaciones. 10 veces utiliza en la Autobiografía la expresión «se determinó a» para explicar estas decisiones que toma (por ejemplo, «se determinó ir a París a estudiar» $\left.{ }^{105}\right)$. Parece razonable atribuir estas decisiones a su deseo de agradar a Dios, es decir, a un uso de la razón iluminada por la fe.

- También confió en la jerarquía de la Iglesia ${ }^{106}$, y recurrió al Vicario de Cristo para que le manifestara la voluntad de Dios ${ }^{107}$.

- Y no terminó aquí su búsqueda, sino que esta peregrinación interior se prolongó a lo largo de su vida e incluyó buscar el agrado de Dios hasta en las cosas más pequeñas ${ }^{108}$.

Puede hablarse de una evolución ${ }^{109}$ de tres etapas en la comprensión que tuvo san Ignacio de la voluntad de Dios para él:

- En un primer momento, la voluntad de Dios no parece ser lo que más le preocupa, sino que desea hacer grandes cosas por Él sin preguntarle cuáles: «Proyectaba grandes hazañas que había de hacer por amor de Dios» ${ }^{110}$, «[...] no mirando a cosa ninguna interior, ni sabiendo qué cosa era humildad, ni caridad, ni paciencia [...]» ${ }^{111}$.

101 Cf. Ruiz Jurado, El peregrino de la voluntad de Dios, 212; Josep María Rambla, ed., El peregrino. Autobiografía de San Ignacio de Loyola (Bilbao: M-ST, 1983), 45.

102 Cf. Au. 30.

103 Cf. Au. 96.

104 Cf. $A u .46$.

105 Cf. $A u .71$.

106 Cf. Au. 47, 69. También subraya esta cuestión Ruiz Jurado, El peregrino de la voluntad de Dios, 58.

107 Cf. Au. 85.

108 Cf. S. P. Ignatii, "Deliberatio De Paupertate", en Co. I, 78-83. Edición más reciente en San Ignacio de Loyola, "Deliberación sobre la pobreza”, en Id., Obras, 6. a ed. (Madrid: BAC, 2013), 266-268; y S. P. Ignatii, "Ephemeris”, en Co. I, 86-158. Edición más reciente en San Ignacio de Loyola, “Diario Espiritual”, en Id., Obras, 291-364.

109 Sigo en esta cuestión la tesis de fondo de Decloux: Cf. Simon Decloux, El camino ignaciano: a la mayor gloria de Dios (Madrid: Verbo Divino, 1984).

$110 \mathrm{Au} .17$.

$111 \quad A u .14$. 
- Después entiende que en la orientación general de su vida debe seguir el plan de Dios, ponerse a su servicio, y con este motivo marchar como peregrino a Tierra Santa: tenía «firme voluntad para servirle» ${ }^{112}$. Se va así acercando a un punto de término (la voluntad de Dios), y entiende que esto le va separando de su punto de partida (su propio yo). Comienza una peregrinación que ya no le dirigirá a otro país sino a otra actitud espiritual, es decir, una «peregrinación interior». Esta mutación tiene una enorme importancia porque será también la que procure en el que hace los ejercicios ${ }^{113}$.

- Al fallar por dos veces el proyecto de Tierra Santa (una vez por el Custodio de los Santos Lugares ${ }^{114}$, y la otra -con los compañerospor imposibilidad de embarcar en Venecia ${ }^{115}$ ), comprende que el Señor quiere otra cosa de él, y marcha a Roma a pedir luz al Santo Padre. En adelante san Ignacio procura vivir siempre pendiente o colgado de la voluntad de Dios, en una continua dependencia de Dios, viviendo en estado de alerta para oír las divinas inspiraciones y huyendo de toda forma de independencia o autonomía.

La Autobiografía llama a san Ignacio "el peregrino» ${ }^{116}$, y algunos autores han completado esta denominación diciendo que es «el peregrino de la voluntad de Dios» ${ }^{117}$. Ciertamente, san Ignacio llega a ser el peregrino que quiere en todo hallar la voluntad divina y cumplirla perfectamente: «Todo lo hace en Cristo Jesús o en Jesucristo, Nuestro Señor. Su máximo anhelo es servir de tal forma que todo se haga en conformidad con la voluntad divina, que se habrá procurado hallar y sentir delante de Dios Nuestro Señor» ${ }^{118}$.

112 Au. 27.

113 «Una consecuencia, pues, de esta gracia de Manresa fue sin duda la posición que en los Ejercicios ocupa la voluntad divina, que se constituye como fin último de los mismos, y punto donde convergen los esfuerzos, búsquedas y gracias durante los mismos», en: Nurya Martínez-Gayol Fernández, Gloria de Dios en Ignacio de Loyola (Bilbao: M-ST, 2004), 96.

114 Cf. Au. 47-48.

115 Cf. Au. 96.

116 Cf. $\quad A u$. 15.38-39.42-46.49-50.52.54.57-59.61-62.64-67.70-71.73.77-81.8387.89.92-94.96-99. No podemos afirmar que esta denominación proceda del mismo san Ignacio, pues podría tener su origen en el autor de la redacción del texto.

117 Cf. Manuel Ruiz Jurado, El peregrino de la voluntad de Dios, 106.129.205.209.212.

118 Jaime Emilio González Magaña, "Quid agendum? La búsqueda continua de la voluntad de Dios”, Apuntes Ignacianos 51 (2007): 48. 
La Autobiografía y el Diario Espiritual sugieren que Ignacio ha dejado a Dios tomar posesión de su voluntad. Dios se ha convertido en su instructor porque él tiene firme voluntad de servirle.

\section{d. San Ignacio y su magisterio sobre la voluntad de Dios}

Ninguno de los grandes escritores espirituales que precedieron a san Ignacio puso tan fuertemente el acento sobre la adhesión a la voluntad de Dios para quienes se adhieren a su servicio. De esta forma, san Ignacio une en el centro de la vida espiritual las ideas de servicio y de conformidad con la voluntad de Dios, como afirma en la primera anotación de los Ejercicios: «[...] para buscar y hallar la voluntad divina en la disposición de su vida $[\ldots]^{119}$.

Uno de los escritos de Ignacio en el que la voluntad divina se propone de una forma patente como criterio orientador de la existencia es el libro de los Ejercicios, y particularmente la meditación conocida como "la llamada del Rey» ${ }^{120}$. En ese momento de la experiencia de ejercicios, que es pórtico de la segunda semana como lo fuera el «Principio y Fundamento» de la primera, el Señor manifiesta al ejercitante su voluntad y solicita su colaboración. Se desvelan aquí varios aspectos fundamentales de la comprensión de la voluntad de Dios para san Ignacio:

- Hay una llamada personal de Dios que cada uno puede buscar y sentir («ver a Cristo nuestro Señor, rey eterno, y delante dél todo el universo mundo, al cual y a cada uno en particular llama») ${ }^{121}$. De ahí que Ignacio se vaya configurando como un «rastreador incansable del sentir la voluntad de Dios» ${ }^{122}$.

- Dios tiene un plan para el mundo y para la humanidad, no se abstrae de la situación de sus criaturas. Y quiere contar con la colaboración humana en el desarrollo de este proyecto de salvación universal. San Ignacio identifica la obediencia a Dios no solo con el cumplimiento de los mandamientos sino también con el servicio divino: «[...] quien quisiere venir conmigo, ha de trabajar conmigo $[\ldots] »^{123}$.

119 Ej. 1.

120 Cf. Ej. 91-98.

121 Ej. 95.

122 Martínez-Gayol, 96.

123 Ej. 95. 
- Dios no impone su voluntad, sino que permite que sea cada uno quien busque esa voluntad divina. La gracia ayudará a escoger con libertad, y para ello será precisa una purificación interior de pasiones y afecciones desordenadas: «[...] elegir es, entonces, abrazar la voluntad de Dios, no dejándose conducir por ninguna afección desordenada [...]» ${ }^{124}$.

- La respuesta humana, aun siendo positiva, puede ser distinta, pudiendo responder conforme a la razón o con amor apasionado: «[...] los que tuvieren juicio y razón [...], los que más se querrán afectar y señalar $[\ldots]_{»}{ }^{125}$.

- La respuesta más generosa no consiste en hacer cosas relevantes por Cristo sino en configurar la propia vida a imagen suya y vivir con él y como él (el conmigo de su llamada).

Además de en los Ejercicios ${ }^{126}$, hay otros documentos donde puede descubrirse cómo entiende san Ignacio la voluntad divina. Así, por ejemplo, en el Directorio autógrafo, del cual La Palma copió algunas frases textualmente:

«Se podría usar de presentar un día a Dios nuestro Señor una parte, otro día otra, como sería un día los consejos y otro los preceptos, y observar adonde le da más señal Dios nuestro Señor de su divina voluntad, como quien presenta diversos manjares a un príncipe y observa cuál dellos le agrada» ${ }^{127}$.

También resulta interesante una carta en la que desarrolla Ignacio esta comprensión de la voluntad divina: la que dirigió a san Francisco de Borja en 1552, con motivo del capelo cardenalicio que el emperador Carlos V quería que Borja recibiese. A san Ignacio le parecía que recibir dignidades eclesiásticas era incompatible con el espíritu de la Compañía, pero le dice:

\footnotetext{
124 Martínez-Gayol, 96.

125 Ej. 96-97.

126 Dios mueve y atrae la voluntad (cf. Ej. 175.180); ofrecer la voluntad a Dios (cf. Ej. 234); lo que es más grato a su divina bondad (cf. Ej. 151); intención pura para mirar solo el beneplácito divino (cf. Ej. 46); quitar de sí las afecciones desordenadas para cumplir la voluntad de Dios (cf. Ej. 1.16.154-155.157.324); no determinarse por las afecciones desordenadas (cf. Ej. 21.169.172.179); el modelo es Cristo, que vive en obediencia al Padre y se hace súbdito de José (cf. Ej. 135.271).

127 MEx II, 76. Edición más reciente: San Ignacio de Loyola, "Directorio autógrafo", c. $3^{\circ}$, n. 21, en Id., Obras, 244.
} 
«Con todo esto yo he tenido y tengo que, seyendo la voluntad diuina que yo en esto me pusiese, poniéndose otros al contrario y dándoseos esta dignidad, que no había contraditión alguna, pudiendo ser el mismo spíritu diuino mouerme á mí á esto por vnas razones y á otros al contrario por otras, veniendo á efecto lo que el emperador señalaua» ${ }^{128}$.

Este fragmento es interesante también porque de aquí se concluye que -según san Ignacio- lo que a Dios le importa de veras no es tanto cuál sea el desenlace de este asunto del capelo, sino la actitud que el Señor espera de Ignacio. Y es esa actitud -la de oponerse al capelo- la que Dios puede pedirle, con independencia de que finalmente Borja reciba o no reciba dicha distinción.

Otros muchos documentos pueden aducirse a propósito de la voluntad de Dios en los escritos de san Ignacio de Loyola ${ }^{129}$, pero la extensión de este artículo no lo permite. Solamente añadiremos al respecto lo que el P. Pedro de Ribadeneira (1526-1611) ${ }^{130}$ aporta en sus escritos sobre «la voluntad de Dios en san Ignacio», en particular en la obra hagiográfica que escribió sobre el santo fundador. El motivo de atender a la obra de este autor es doble: por un lado, se trata de alguien que lo conoció bien; y, además, Ribadeneira tuvo posteriormente una gran influencia en el $\mathrm{P}$. Luis de La Palma, con quien convivió en Madrid hasta su muerte. Pues bien, esto es lo que Ribadeneira cuenta que aprendió de san Ignacio:

- «[...] el escoger estado y tomar manera de vida avíase de hazer con mucha oración y consideración, y desseo de agradar a Dios y de acertar cada uno a tomar lo que el Señor quiere que cada uno tome $[\ldots] »^{131}$.

128 Epp. IV, 284.

129 Conformar la propia voluntad con la voluntad de Dios por la obediencia y la abnegación (cf. San Ignacio de Loyola, Obras, 936), la voluntad de Dios es regla de toda rectitud (ibid., 822), cómo proceder en la búsqueda de la voluntad divina (ibid., 666), pedir gracia para sentir y cumplir la voluntad divina (ibid., 720), la voluntad de Dios se identifica con lo que más agrada a Dios (ibid., 735), agradar a Cristo (ibid., 742s), la plena sumisión de la voluntad (ibid., 735), conformar la voluntad con la voluntad de Dios (ibid., 981), Cristo precedió en el ejemplo de la obediencia (ibid., 942), buscar los intereses de Jesucristo (ibid., 931), la divina bondad primera y suma regla de nuestra voluntad (ibid., 284), cuánto ayuda vivir en presencia de Dios como contemplativos en la acción para cumplir su voluntad (ibid., 886), etc.

130 Cf. Manuel Ruiz Jurado, "Ribadeneira, Pedro de", en DHCJ, vol. II, 3345-3346.

131 Pedro de Ribadeneira, Vida del Padre Ignacio de Loyola, en FN IV (1583-1605), (Roma: MHSI, 1965), 137. 
- «[...] hazer en todo lo que fuesse más agradable a los ojos de su divina Magestad, y ponerlo todo en sus manos, y hazer lo que él le dixesse $»^{132}$.

- «[...] començó a pensar con gran cuydado qué era lo que Dios quería dél: qué cosa sería bien hazer que fuesse más acepta y agradable en los ojos de su divino acatamiento ${ }^{133}$.

Estas expresiones denotan que para san Ignacio -desde la perspectiva de Ribadeneira- la voluntad de Dios no se impone, sino que se insinúa, y que Ignacio tiene intención de complacer al Señor, de cumplir su voluntad con sumo gusto e interés, por amistad.

Parece que también esto es lo que propone san Ignacio con la expresión Ad maiorem Dei Gloriam, que debe ser comprendida de esa forma, como la búsqueda por amistad del agrado de Dios. Seguimos leyendo a Ribadeneira:

«Porque ya desde entonces començaba nuestro Señor a plantar en el coraçón de Ignacio un vivo y ardentíssimo desseo de buscar y procurar en todas sus cosas lo que fuesse a los ojos de su Magestad más agradable; que este fue como su blasón siempre, y como el ánima y vida de todas sus obras: A mayor gloria divina. Pero ya en estas penitencias que hazía avía subido un escalón más; porque en ellas no mirava, como antes, tanto a sus pecados, quanto el desseo que tenía de agradar a Dios. [...] Estaba ya su coraçón tan inflamado y abrassado de un vehementíssimo desseo de agradar a Dios, que no tenía cuenta tanto con los mismos pecados, ni se acordava dellos, como de la gloria $y$ honra de Dios» ${ }^{134}$.

El fragmento presentado tiene otro importante valor, y es que nos ofrece la más antigua interpretación del célebre lema ignaciano. Para Ribadeneira esta expresión no hay que identificarla con deseos pretenciosos de un éxito megalómano. Ribadeneira, buen conocedor del corazón de su maestro, entiende que para Ignacio esta expresión es sinónimo de lo que fuese a los ojos de Dios más agradable.

Cumplir la voluntad de Dios y buscar la gloria de Dios no son, por tanto, cosas diferentes de buscar su agrado, buscar su complacencia, serle gratos. Así lo entendió también el P. Nadal, que nos ofrece una imagen

\footnotetext{
132 Ibid., 147.

133 Ibid., 169.

134 Ibid., 99.101.
} 
de san Ignacio ${ }^{135}$ en la que estos conceptos de gloria y agrado de Dios se identifican:

«Queriendo pues el Señor que ubiesse quien desta manera le sirviesse, llamó al Padre M. Ignatio en una enfermedad, etc., dándole in primis dessear con gran devotion la mayor honrra y gloria de su divina magestad. Y assí como estando en el século tenía ánimo de grandes cosas, assí dándose al servicio de Dios no se contentava con poco, sino intensamente desseava y procurava cómo más le pudiesse agradar en todo y con toda perfectión. Y assí lo repite esto muchas vezes en las constitutiones, scilicet, a mayor honrra y gloria de su divina Magestad» ${ }^{136}$.

También lo entienden así otros estudiosos actuales de san Ignacio: «En cada momento, el mayor servicio divino y el mayor beneplácito divino serán como "miembros" de una misma igualdad. Buscar la gloria de Dios, hic et nunc, en el servicio divino será procurar y buscar su "santísima voluntad" ${ }^{137}$.

Los escritos autógrafos de san Ignacio confirman las referencias de Nadal y Ribadeneira:

Así, por ejemplo, en la meditación de «Tres binarios», san Ignacio propone como $2{ }^{\circ}$ preámbulo: «El 2. ${ }^{\circ}$, composición viendo el lugar: será aquí ver a mí mismo, cómo estoy delante de Dios nuestro Señor y de todos sus santos, para desear y conocer lo que sea más grato a la su divina bondad» ${ }^{138}$.

Esta comprensión es la que encontramos también en el contencioso que mantuvo el santo con los padres de Octavio Césari, y que atestiguan las cartas intercambiadas entre agosto y diciembre de 1553, en las que el santo sostiene: «[...] no se maraville que el hijo prefiera el servicio y beneplácito de Cristo al de esa o cualquier otra criatura ${ }^{139}$, y también:

135 Cf. Jerónimo Nadal, "3. a plática en Coimbra”, en FN vol. II, 148-159; Id., "2. plática en Alcalá”, en FN II, 178-204. Edición más reciente en: Id., Las pláticas del P. Jerónimo Nadal. La globalización ignaciana, ed. y trad. de Miguel Lop Sebastià (Bilbao: M-ST, 2011), 128-134.156-167.

136 MNad V, 38-39.

137 Martínez-Gayol, 96.

138 Ej. 149-157.

139 Epp. V, 418. Original en italiano, traducción al castellano en San Ignacio de Loyola, Obras, 870. 
«[...] y de corazón deseo su remedio, el cual consiste en conformarse con el querer de Dios nuestro Señor ${ }^{140}$.

Quizá, donde con mayor claridad expresa esta cuestión el santo es en la carta que dirige a Diego de Gouvea, portugués que regentaba el colegio de Santa Bárbara de París durante los años que pasó allí san Ignacio. Gouvea había hecho gestiones para que el rey de Portugal, D. Juan III, solicitara jesuitas para sus colonias en la India. San Ignacio responde que no es posible, porque han prestado obediencia al papa para que sea él quien los distribuya en las tareas que considere más necesarias. Y lo explica diciendo:

«La distancia del país no nos espanta, ni el trabajo de aprender lenguas: se haga sólo lo que más agrade a Cristo» ${ }^{141}$.

Hace algo más de medio siglo vio la luz otro documento muy interesante. Me refiero a las llamadas Anotaciones del doctor Ortiz que publicó la revista Miscelánea Comillas ${ }^{142}$. Son los apuntes personales que tomó el Dr. Pedro Ortiz cuando recibió los ejercicios de san Ignacio.

$\mathrm{Su}$ interés estriba en que, conociendo el texto de los Ejercicios, no sabíamos exactamente cómo daba san Ignacio las meditaciones: con qué expresiones las desgranaba, con qué estilo se comunicaba, qué tono empleaba para comunicar las verdades que contienen. Pues bien, estas Anotaciones tienen precisamente ese valor: que, como una "grabadora» del siglo XVI, nos introducen en una tanda de ejercicios impartida por el mismo san Ignacio.

En las páginas de dichas Anotaciones, llama la atención la frecuencia con la que se emplean las expresiones agrada a Dios, agradar a Dios, agradable a Dios: ni más ni menos que 31 veces. Es especialmente llamativo que san Ignacio le reitera al Dr. Ortiz en las elecciones de ejercicios el criterio de buscar en todo la conformidad con la voluntad divina, que él define con este término afectivo:

140 Epp. VI, 50. Original en italiano, traducción al castellano en: San Ignacio de Loyola, Obras, 872.

141 Epp. I, 133. Original en latín, traducción al castellano en: San Ignacio de Loyola, Obras, 674.

142 Cf. Camilo Abad, "Unas Anotaciones inéditas sobre los ejercicios de san Ignacio compuestas por el Doctor Pedro Ortiz y su hermano Fray Francisco”, Miscelánea Comillas 25 (1956): 25-114. Accesible en https://biblioteca.comillas.edu/digital/abnetopac.exe?TITN=505173 
«[...] puede entonces el tal siervo de Dios, por la infinita bondad del Señor, alcançar y sentir su sanctisima voluntad en la parte que más le agrada y más conviene a su servicio» ${ }^{143}$.

Nuestro estudio no será tan pormenorizado en los autores posteriores: nos limitamos a ofrecer algunos fragmentos significativos de sus escritos en los que utilizan conceptos y términos muy semejantes a los del P. La Palma y san Ignacio de Loyola.

\subsubsection{San Pedro Fabro (1506-1546)}

Fabro fue el primer sacerdote de la Compañía de Jesús, saboyano de nacimiento, que coincidió con san Ignacio y san Francisco Javier en París. De naturaleza dialogante y cordial, hizo mucho bien en Alemania por huir de la polémica con los protestantes y por buscar con todos el entendimiento. Es quizá el discípulo de san Ignacio que más claramente habla de la voluntad de Dios con términos afectivos, y puede decirse que es, por tanto, el precedente más inmediato del P. La Palma en este sentido. Atribuye a san Ignacio haberle ayudado a conocer mejor la voluntad de Dios:

«Al vivir en la misma habitación compartíamos la misma mesa y la misma bolsa. Me orientó en las cosas espirituales, mostrándome la manera de crecer en el conocimiento de la voluntad divina y de mi propia voluntad $»^{144}$.

En otros pasajes, manifiesta que está poniendo todo su interés en descubrir y cumplir la voluntad divina:

«Ojalá, Dios mío, que yo pudiese conocer distintamente en todas mis obras vuestra voluntad. Esto sería para mí una vida felicísima» ${ }^{145}$.

En el número 233 del llamado Memorial de Fabro hace de nuevo referencia a la voluntad de Dios. Y en esta ocasión identifica la voluntad divina con otros términos de índole afectiva:

143 Ibid., 99.

$144 M F a b$ n. 8 páginas en versión original, en Antonio Alburquerque, ed., En el corazón de la Reforma: recuerdos espirituales del beato Pedro Fabro (Bilbao: M-ST, 2000), 116.

$145 M F a b$ n. 236, en Alburquerque, ed., 245. 
«Experimenté un gran deseo de no tener nada de que poder echar mano (está hablando de la pobreza material). Y así rogué, desde lo más hondo de mi corazón a Cristo, a quien tenía delante de mis ojos en el altar, que, si es su voluntad y beneplácito, no se pase año, mientras yo viva, sin verme privado, yo y los otros, al menos una vez, de las cosas necesarias para la vida. Y si esta gracia que yo tengo en mucho, no me viniera de parte de las mismas cosas, que se me dé a conocer si es que le agrada a Dios que yo haga voto, en cuanto de mí dependa, de privarme, una vez al año, de las cosas necesarias [...]. Ojalá me dé Dios a conocer lo que más conviene para su alabanza y para que en todo se haga su voluntad, buena, agradable, y perfecta» ${ }^{146}$.

Este párrafo no es una excepción. Rastreando sus escritos, descubrimos que emplea varias palabras agapetónicas para referirse al cumplimiento de la voluntad de Dios:

Agradar

«Conviene que nos pongamos en su presencia de tal manera que a sólo Él queramos agradar y a sus santos que están en la gloria» ${ }^{147}$.

\section{Contentar}

«[...] Nuestro primer empeño ha de ser amarlo a Él. Es decir, que no andemos averiguando cómo procede con nosotros sino cómo actúa Él en sí mismo y en todas las otras cosas, y qué es lo que en realidad le contenta o le desagrada en sus criaturas, [...] acordarnos nosotros de Él y poner empeño en lo que a Él le $\operatorname{agrada»~}{ }^{148}$.

\section{Buscar su beneplácito}

«Ojalá se renueve mi mismo ser, mi vivir, sentir y mi mismo poder y todas las cualidades y accidentes que perfeccionan el fundamento para la vida eterna y celeste según el beneplácito de Dios» ${ }^{149}$.

Ser grato a Cristo, grato a Dios

- «Y me parece que es muy bueno y grato a Cristo y a los santos dejar, en todas las posadas y casas donde tenemos que detenernos, mues-

\footnotetext{
$146 \quad M F a b$ n. 233, en Alburquerque, ed., 243-244.

$147 M F a b$ n. 75, en Alburquerque, ed., 158.

$148 M F a b$ n. 203, en Alburquerque, ed., 228.

149 MFab n. 191, en Alburquerque, ed., 222.
} 
tras de buena y santa conversación, edificando en todas partes, plantando algo y recogiendo» ${ }^{150}$.

- «De aquí nacía en mí un vehemente deseo de que la misma Virgen María me hiciese grato a Dios, ya que ella es la llena de gracia; y puesto que Cristo siempre estuvo con ella, me lo haga a mí presente y cercano» ${ }^{151}$.

\subsubsection{San Francisco Javier (1506-1552)}

El santo navarro fue formado por san Ignacio en París y Roma, y encarnó el espíritu de los Ejercicios sin perder por eso la riqueza de su temperamento singular, encendido y apostólico. Aunque en sus cartas la cuestión de la voluntad de Dios no ocupa un espacio central, las veces que se refiere a ella lo hace empleando los mismos términos que san Ignacio y esa comprensión más afectiva que hemos visto en el P. La Palma. Afirma que Dios puede mostrar su voluntad a través de otros compañeros, y da a sentir su voluntad como signo de su benevolencia:

«[...] principalmente á aquellas personas por medio de las qualles a plazido á su diuina Majestad darnos á sentir en qué de nosotros se manda seruir: rogamus vos, Patres, et obsecramus iterum atque iterum in Domino, per illam nostram in Xpo. Jesu conjunctissimam amicitiam, que nos escribáis los abisos y medios para más seruir á Dios nuestro Señor, que allá os paresciere que debemos de fazer, pues tanto desseamos la voluntad de Xpo. nuestro Señor por vossotros sernos manifestada ${ }^{152}$.

Termina sus cartas con fórmulas similares a la célebre frase de despedida de san Ignacio:

«Y assí cesso, rogando á Dios nuestro Señor que nos dé á conoscer y sentir su sanctíssima voluntad $\mathrm{y}$, sentida, muchas fuerças y gracia para en esta vida cumplirla de charidad» ${ }^{153}$.

$150 \quad M F a b$ n. 433, en Alburquerque, ed., 334.

$151 \quad M F a b$ n. 48, en Alburquerque, ed., 141.

152 Sancti Francisci Xaverii, "P. Ignatio de Loyola et Joanni Coduri", en MXav I, 239-240. Edición más reciente en castellano en San Francisco Javier, "Carta a Ignacio de Loyola y Juan de Coduri, del 18/03/1541”, en Id., Cartas y escritos de San Francisco Javier, ed. Félix Zubillaga, 3. ${ }^{\text {a }}$ ed. (Madrid: BAC, 1979), 73-74.

153 Id., "Sociis Romae degentibus", en MXav I, 371. Edición más reciente en castellano en Id., “Carta a los compañeros residentes en Roma, del 27/01/1545”, en Id., Cartas y escritos, 169. 
Emplea diversas expresiones para referirse a la voluntad de Dios. Las dos más frecuentes son: su santa / santísima voluntad, que encontramos en sus cartas 14 veces; y voluntad de Dios / voluntad divina, que aparece en 8 ocasiones. Aunque mucho menos citada, llama la atención que emplea el término agrado para referirse a la voluntad divina con una plena identificación de significados:

«Aún no he resuelto definitivamente si yo mismo iré al Japón con uno o dos de la Compañía después de año y medio [...]. Pido a Dios que me inspire con toda claridad lo que sea más de su agrado» ${ }^{154}$.

\subsubsection{P. Jerónimo Nadal (1507-1580)}

$\mathrm{Nadal}^{155}$, jesuita mallorquín, fue una gran ayuda para san Ignacio en la promulgación de las Constituciones de la Compañía. Fue notable su contribución a la llamada "pedagogía ignaciana» al poner en marcha en Mesina un método de estudios novedoso que se extendería en los colegios de la Compañía. Son célebres sus Pláticas, con las que fue infundiendo el espíritu de san Ignacio que quedó impreso en las Constituciones. Con firmeza y amabilidad, plantea la grandeza y las exigencias de la vocación del jesuita, y entre otras cosas, la búsqueda sincera del agrado de Dios:

«[...] que el desseo de contentar a Dios y de agradarle en todo sea el que os llebe a la oración y recogimiento» ${ }^{156}$.

«Es buen principio de oración començar [...] con la charidad, que sólo por amor de Dios y con desseo de agradarle vais allí»» ${ }^{157}$.

\subsubsection{San Francisco de Borja (1510-1572)}

Francisco de Borja, duque de Gandía y virrey de Cataluña, entró en contacto con Pedro Fabro y Araoz ${ }^{158}$. Después de hacer los ejercicios y de ayudar a la Compañía de Jesús desde su posición, a la muerte de su

154 Id., "Carta al P. Ignacio de Loyola, del 20/01/1548”, en Id., Cartas y escritos, 227. Original en latín en Id., "P. Ignatio de Loyola", en MXav I, 449.

155 Cf. Manuel Ruiz Jurado, “Nadal, Jerónimo”, en DHCJ, vol. III, 2793-2796.

156 Jerónimo Nadal, "14. a plática en Alcalá”, en MNad V, 476-477. Edición más reciente en: Miguel Lop, ed., Las pláticas, 285.

157 Ibid., 486-487.

158 Cf. José Martínez de la Escalera, “Araoz, Antonio de”, en DHCJ, vol. I, 433. 
esposa Leonor de Castro entró en la Compañía. Fue comisario de los jesuitas en España y el tercer P. General de la Compañía, tras la muerte del P. Laínez.

Las tareas de gobierno que le encargaron explican que sus escritos sean cartas en su mayoría. Sus Tratados espirituales no fueron publicados en Monumenta, donde sí se recogió su abundante epistolario en 5 volúmenes, sino que fueron divulgados a partir del año $1961^{159}$. Un sencillo párrafo nos permite ver que Borja también había recibido esta comprensión de la voluntad divina y de la importancia que tiene su cumplimiento. Concibe el pecado no como una mera transgresión de la ley, sino como una herida que infligimos en el corazón a Cristo (clavo, azote, lanza, vinagre...). Dice así:

«[...] Y si a Cristo hirieron en el costado después de muerto, yo le hiero en el corazón cuando voy contra su voluntad, reinando y viviendo en la eternidad; de lo cual se quejaba a san Pablo diciendo: "Saule, Saule, cur me persequeris?" Yo soy, pues, el clavo que le atravesé las manos con la abominación de mis obras, y soy el azote que le hiere su carne por la flaqueza de la mía, y soy la lanza que abrí su costado por no conformarme con su voluntad, soy el vinagre para su gusto con mis murmuraciones, y al fin la muerte para su vida. [...] Quisiste por Vos mismo llamarme, tocándome en el corazón, despertándome a hacer vuestra divina voluntad tan dulcemente como si yo nunca la hubiera contradicho; lo que si yo conociera como debía, una sola vez bastara para nunca más partirme de vuestro beneplácito» ${ }^{160}$.

\subsection{Otros autores Jesuitas contemporáneos a La Palma}

\subsubsection{San Pedro Canisio (1521-1597)}

Canisio fue un teólogo holandés de nacimiento, alemán por su dedicación a la nación germana durante la controversia con los protestantes, que se caracterizó por su defensa de la Iglesia con agudeza e ingenio, pero simultáneamente con paciencia y respeto. Frente a la idea severa

159 Cándido de Dalmases, y Jean François Gilmont, ed., "Las obras de san Francisco de Borja", AHSI 59 (1961) 125-179.

160 San Francisco de Borja, Tratados espirituales, ed. Cándido de Dalmases (Barcelona: Juan Flors, 1964), 60. 
que de él se hicieron los protestantes, late en su alma un espíritu delicado que busca en todo complacer a Jesucristo:

«Bajo su dirección (se refiere a la del P. Van Esche) fui sintiendo poco a poco descontento de mí mismo, para agradarte más a ti, mi Dios, a quien conocía todavía poco y temía menos en aquella flor de la juventud» ${ }^{161}$.

Y llega Canisio a esta manera de comprender la voluntad de Dios por tener a Cristo como amigo. Llama poderosamente la atención en el próximo fragmento que sugiere unir la propia voluntad al Corazón de Jesús, a quien califica -con términos que expresan relación de afectocomo amigo y esposo:

«Debemos honrar, amar, alabar y proclamar este nombre (de Cristo). Pero ¿cómo puede y debe hacerse esto? Meditando en el corazón sobre la persona, las palabras y el espíritu de Jesús, si se tiene grabado este nombre en el corazón de tal modo que medita frecuentemente sobre la vida y pasión del Señor, y guarda, como la Magdalena, la palabra de Cristo, y ama intimamente a Cristo, amigo y esposo, y une su voluntad con el Corazón de Jesús» ${ }^{162}$.

\subsubsection{P. Alonso Rodríguez (1526-1616)}

Este jesuita natural de Valladolid, notable por su humildad y otras virtudes, fue maestro de novicios en Salamanca y Montilla, y es conocido sobre todo por su Tratado de perfección y virtudes cristianas $^{163}$. En este libro dedica todo el tratado VIII a la conformidad con la voluntad de Dios. Trata de explicar los bienes que se siguen para quien busca en todo la voluntad divina y distingue entre conformidad pasiva (aceptar lo que Dios hace) y conformidad activa (realizar lo que Él desea).

En este capítulo, su interés mayor está en la conformidad pasiva, que ve especialmente necesaria en la enfermedad, los trabajos y la muerte. Para ayudar a crecer en esta conformidad con la voluntad divina mueve

161 Pedro Canisio, Autobiografía y otros escritos, ed. Benigno Hernández Montes (Bilbao: M-ST, 2004), 65.

162 Ibid., 167-168.

163 No debe confundirse al P. Alonso Rodríguez con su coetáneo segoviano san Alonso Rodríguez (1532-1617), que se santificó en la portería del colegio de Montesión en Mallorca. 
a confianza al lector, mostrando con un tono afectuoso la suprema bondad de Dios:

«[...] vengamos á tomar todas las cosas que nos suceden como si sensible y visiblemente viésemos á Cristo nuestro Señor que nos está diciendo: "Toma, hijo, esto te envió; mi voluntad es que hagas ó padezcas ahora esto y esto"; porque de esta manera se nos hará muy fácil y muy suave el conformarnos en todas las cosas con la voluntad de Dios; porque si se os apareciera el mismo Jesucristo en persona, y os dijera: "Mira, hijo, que esto es lo que quiero de tí: este trabajo ó enfermedad quiero que padezcas ahora por mí; en este oficio ó ministerio quiero que me sirvas"; claro está que aunque fuese la cosa mas dificultosa del mundo, la haríais de muy buena voluntad» ${ }^{164}$.

Para concluir este breve recorrido histórico, ofrecemos dos breves citas de otros dos autores contemporáneos a La Palma.

\subsubsection{P. Luis de La Puente (1554-1624)}

La Puente, jesuita y teólogo también natural de Valladolid, fue el autor ascético de algunas obras célebres en su tiempo, como Guía Espiritual, los tres volúmenes de Meditaciones Espirituales, y también Vida del P. Baltasar Álvarez. Fue director espiritual del noviciado de la Compañía de Jesús en Villagarcía de Campos y murió con fama de santidad. La voluntad de Dios está muy presente en su obra. Aunque no advertimos el mismo tono cordial y afectuoso de La Palma, ofrece algún párrafo que recuerda mucho su estilo:

«Yo (dize el Salvador) soy el camino de tu salvación, y perfección, y por mi medio has de ir a mi Padre, y le has de agradar, y aplacar, y hallar gracia en sus ojos» ${ }^{165}$.

\subsubsection{San Pedro Claver (1580-1654)}

El santo catalán, apóstol de los esclavos en Cartagena de Indias (Colombia), no ha pasado a la historia por sus escritos sino por la autenticidad de

164 Alonso Rodríguez, Tratado de perfección y virtudes cristianas, parte 1. ${ }^{\text {a }}$, c. IX (Barcelona: Imprenta de Pablo Riera, 1861), 380.

165 Luis de La Puente, “Tratado 3. Del sacrificio de la Misa”, en Obras espirituales (Madrid: Imprenta de Bernardo de Villa-Diego, 1690), 5:138. 
su vida y la generosidad de su entrega. Sin embargo, conservamos el texto de un escrito personal del día de sus primeros votos, 8 de agosto de 1604, en el que da a entender -con un estilo que enternece- su particular manera de comprender la voluntad de Dios. Como se verá, coincide plenamente con el estilo que inculcó san Ignacio en sus hijos, que Pedro Claver debió recibir de san Alonso Rodríguez, y que hemos visto en el P. La Palma:

«Hasta la muerte me he de consagrar al servicio de Dios, haciendo cuenta que soy como esclavo, que todo su empleo es de ser en servicio de su amo y en procurar con toda su alma, cuerpo y mente, agradarle y darle gusto en todo y por todo» ${ }^{166}$.

Aquí termina el elenco de autores que son coetáneos del P. La Palma, de quienes en algunos casos pudo aprender, y con quienes en otros casos pudo compartir la fuente de su conocimiento. Como hemos visto, el campo estaba abonado para que el P. La Palma diera mucho fruto.

\section{CONCLUSIONES}

El estudio que hemos realizado siguiendo la obra Camino Espiritual del P. Luis de La Palma nos ha permitido acercarnos a la comprensión del concepto "voluntad de Dios» en la obra de este autor. No dista de la de san Ignacio de Loyola, para quien el Señor no es un mero legislador que impone normas a sus criaturas, sino su mejor amigo, su Señor, la pasión de su vida. De este modo, san Ignacio recibe la voluntad de Dios como el deseo del amigo, el anhelo de su Señor.

\subsection{CRisto VIVE y SE COMUNicA}

Un «cristianismo sin Cristo» queda reducido a un frío moralismo de leyes -cumplimiento de normas- o a un moralismo de actitudes -de valores evangélicos- al margen del Señor. La corriente de espiritualidad ignaciana en la que se inscribe el P. La Palma, por el contrario, supone la intervención personal de Cristo en la vida de cada persona, y ayuda con su magisterio a vivir pendientes del agrado de Cristo resucitado vivo, de Corazón palpitante.

166 Ángel Valtierra y Rafael María Hornedo, San Pedro Claver, 2. ${ }^{a}$ ed. (Madrid: BAC, 1997), 33. 


\subsection{IMPORTANCiA DE CUMPLIR LA VOluntad DE Dios}

Cumplir la voluntad de Dios es camino imprescindible para quien quiere vivir como discípulo de Jesucristo. No es un aspecto secundario de la vida espiritual sino más bien el fin al que conducen todas las prácticas espirituales.

No ha de concebirse el cumplimiento de la voluntad divina como una tarea voluntarista. En la espiritualidad ignaciana, y por tanto en la del P. La Palma y otros autores citados, la prioridad la tiene la gracia: es el Señor quien invita a su amistad, quien muestra su agrado. Es Él quien capacita para cumplir su voluntad, y el hombre puede libremente colaborar con la gracia divina. Al mostrarse la totalidad de los Ejercicios y el sentido que quiso darles san Ignacio, queda clara la invitación a dejarse conducir hasta la unión plena con el Señor, que algunos autores identifican como la vía unitiva. El camino para llegar a este término es -en el contexto de un trato de amistad- la búsqueda de la voluntad de Dios, que es su complacencia.

\subsection{QUeRER Lo Que Dios HACE, HACER Lo QUe DiOS QUIERE: MANDAMIENTOS Y AGRADO}

La voluntad de Dios puede ser entendida como algo que Dios hace y el hombre debe aceptar (conformidad pasiva), o como algo que Dios quiere y el hombre debe cumplir (aceptación activa). Una primera manera de interpretar «lo que Dios quiere» es identificarlo con las normas o leyes vinculantes bajo pecado. Sin ser equivocada, parece que esta idea es insuficiente, que no responde totalmente a la profunda relación de amistad que el Dios revelado en Jesucristo nos ofrece. El segundo modo de entender «lo que Dios quiere» es descubrir en ello el deseo divino que el hombre, en la medida en que viva en amistad con Él, puede sentir y cumplir. Entendida la voluntad de Dios de esta forma, es comprensible que los términos con los que se exprese no pertenezcan al lenguaje de la ley moral (mandamiento, norma, precepto, prohibición), sino al lenguaje propio de la amistad (agrado de Dios, complacencia, gusto, anhelo del corazón).

La escuela ignaciana, de cuya fuente bebió casi en primera persona el P. La Palma, presenta la voluntad de Dios desde esta perspectiva que enriquece y dota de un carácter afectuoso la relación con el Señor. La voluntad de Dios no es un mandato extrínseco que aliena sino el agrado de Jesús, amigo sumamente querido. 


\subsection{Elección y unión con Dios, Dos Fines complementarios}

La comprensión de la voluntad de Dios desde una perspectiva más agapetónica y menos deontotónica puede contribuir a acercar las posturas de quienes defienden que el fin último de los ejercicios es la elección y quienes consideran que la unión con Dios es el objetivo que se debe buscar. Estas dos finalidades de los ejercicios pueden converger cuando se asume que la búsqueda de la voluntad divina en el proceso de elección requiere una cierta amistad previa, y que es deseo de Dios que conduzca a una plena unión de amor.

\subsection{Luis de La Palma, tesoro espiritual por descubrir}

El P. Luis de la Palma ofrece una riqueza teológica y espiritual de primera magnitud. Su comentario a los Ejercicios de san Ignacio puede considerarse un clásico de la espiritualidad ignaciana, todavía insuficientemente estudiado y difundido. Su cercanía respecto de los primeros jesuitas explica la profundidad con la que reflexiona sobre los Ejercicios y la sintonía espiritual que se advierte entre sus escritos y los de san Ignacio de Loyola.

\section{SIGLAS Y ABREVIATURAS}

\section{A. De los escritos ignacianos}

Au. Autobiografía. Acta Patris Ignatii scripta a P. Lud. González de Cámara, en FN I (Roma, 1943), 354-507.

Co. Constituciones, en Monumenta Constitutionum, vol. I (Roma, 1936).

D Miguel Lop Sebastià, ed., Los Directorios de Ejercicios (15401599) (Bilbao: M-ST, 2000).

DHCJ Charles O’Neill, y Joaquín M. ${ }^{a}$ Domínguez, ed., Diccionario histórico de la Compañía de Jesús. Biográfico-temático, 4 vol. (Madrid: Universidad Pontificia Comillas, 2001).

Ej. Ejercicios Espirituales. Exercitia Spiritualia (Roma, 1969).

Epp. Sancti Ignatii de Loyola Societatis Iesu fundatoris epistolae et instructiones, 12 vol. (Madrid, 1903-1911).

FN Fontes Narrativi de S. Ignatio de Loyola et de Societatis Iesu initiis, 4 vol. (Roma, 1943-1965). 
Mem Memoriale seu diarium Patris Ludovici González de Cámara, en FN I (Roma, 1943), 508-752.

MEx II Monumenta Exercitiae (II, Directoria 1540 -1599) (Roma, 1955).

MFab Monumenta Beati Petri Fabri. Epistolae, Memoriale et processus (Madrid 1914).

MHSI Monumenta Historica Societatis Iesu. (Madrid, 1894 y siguientes; Roma, 1932 y siguientes).

MNad Monumenta Natalis. Epistolae Hieronymi Nadal Societatis Iesu ab anno 1546 ad 1577 (et alia scripta), 5 vol. (Madrid Roma, 1898-1962).

MRib Monumenta Ribadeneira. Patris Petri de Ribadeneira Societatis Iesu sacerdotis. Confessiones, epistolae aliaque scripta inedita, 2 vol. (Madrid 1920-1923).

MXav Monumenta Xaveriana. Epistolae S. Francisci Xavierii aliaque eius scripta, 2 vol. (Roma, 1944-1945).

B. De Colecciones de Documentos, Diccionarios y Editoriales

AAS Acta Apostolicae Sedis (Roma, 1909-2017).

AHSI Archivum Historicum Societatis Iesu (Roma).

BAC Biblioteca de Autores Cristianos (Madrid).

DEI Grupo de Espiritualidad Ignaciana (ed.), Diccionario de Espiritualidad Ignaciana, 2 vol. (Bilbao: M-ST, 2007).

DSp Marcel Viller, ed., Dictionnaire de spiritualité, ascétique et mystique (París: Beauchesne, 1937-1995).

IHSI Institutum Historicum Societatis Iesu (Roma).

M-ST Editorial Mensajero - Sal Terrae

\section{REFERENCIAS}

Abad, Camilo. "Unas Anotaciones inéditas sobre los Ejercicios de San Ignacio compuestas por el Doctor Pedro Ortiz y su hermano Fray Francisco". Miscelánea Comillas 25 (1956): 25-114. Accesible en https://biblioteca.comillas.edu/digital/abnetopac.exe?TITN=505173

Alburquerque, Antonio, ed. En el corazón de la Reforma: recuerdos espirituales del beato Pedro Fabro. Bilbao: M-ST, 2000.

Andrade, Alonso. Varones ilustres en santidad, letras y zelo de las almas. Madrid, 1666. 
Arrupe, Pedro. La identidad del jesuita en nuestros tiempos. Santander: Sal Terrae, 1981.

Arzubialde, Santiago. Ejercicios Espirituales de San Ignacio. Historia y análisis. 2. ${ }^{a}$ ed. Bilbao: M-ST, 2009.

Astrain, Antonio. Historia de la Compañia de Jesús, en la Asistencia de España. Madrid: Imprenta de los sucesores de Rivadeneyra, 1909.

Benedicto XVI. "Carta encíclica Deus caritas est". AAS 98 (2006): 217-296.

Borja, Francisco de. Tratados espirituales. Editado por Cándido de Dalmases. Barcelona: Juan Flors, 1964.

Canisio, Pedro. Autobiografía y otros escritos. Bilbao: M-ST, 2004.

Cereceda, Feliciano. "Carta necrológica sobre el P. Luis de La Palma". Manresa 63 (1945): 155-161.

Decloux, Simon. El camino ignaciano: a la mayor gloria de Dios. Madrid: Verbo Divino, 1984.

Echarte, Ignacio, ed. Concordancia Ignaciana. Bilbao: M-ST, 1996.

Fernández Barberá, Carlos. La fuente que mana y corre. Cincuenta testigos fascinantes. Madrid: Narcea Ediciones, 2000.

García-Villoslada, Ricardo. "Rasgos característicos de la 'Devotio Moderna”. Manresa 108 (1956): 315-350.

- Manual de Historia de la Compañía de Jesús. Madrid: Compañía Bibliográfica Española, 1954.

-. "San Ignacio de Loyola y Erasmo de Rotterdam". Estudios Eclesiásticos 16 (1942): 235-264.

González Magaña, Jaime Emilio. “Quid agendum? La búsqueda continua de la voluntad de Dios”. Apuntes Ignacianos 51 (2007): 39-59.

González, Luis, e Ignacio Iparraguirre. Ejercicios Espirituales. Comentario pastoral. Madrid: BAC, 1965.

Guibert, José de. La espiritualidad de la Compañía de Jesús. Santander: Sal Terrae, 1955.

Iparraguirre, Ignacio. Historia de los Ejercicios de San Ignacio. Roma: IHSI, 1955.

Javier, Francisco. Cartas y escritos de San Francisco Javier. Editado por Félix Zubillaga. 3. ${ }^{\text {a }}$ ed. Madrid: BAC, 1979.

La Palma, Luis de. Obras. Madrid: BAC, 1967.

La Puente, Luis de. Obras espirituales. Madrid: Imprenta de Bernardo de Villa-Diego, 1690.

Leturia, Pedro. Estudios ignacianos. Roma: IHSI, 1957.

Lop Sebastià, Miguel, ed. Los Directorios de Ejercicios 1540-1599. Bilbao: M-ST, 2000. 
Loyola, Ignacio de. Obras, 6. ${ }^{a}$ ed. Madrid: BAC, 2013.

Martínez-Gayol Fernández, Nurya. Gloria de Dios en Ignacio de Loyola. Bilbao: M-ST, 2004.

Melloni, Javier. "Que su voluntad siempre sintamos y aquélla enteramente cumplamos". Manresa 324 (2010): 235-240.

Nadal, Jerónimo. Las pláticas del P. Jerónimo Nadal. La globalización ignaciana. Editado por Miguel Lop Sebastià. Bilbao: M-ST: 2011.

Peeters, Luis. Hacia la unión con Dios por medio de los Ejercicios de S. Ignacio. Bilbao: Mensajero, 1944.

Rahner, Karl. Meditaciones sobre los Ejercicios de san Ignacio. Barcelona: Herder, 1971.

- Palabras de Ignacio de Loyola a un jesuita de hoy. Santander: Sal Terrae, 1990.

Rambla, Josep María, ed. El peregrino. Autobiografía de San Ignacio de Loyola. Bilbao: M-ST, 1983.

Ribadeneira, Pedro. "Vida del Padre Ignacio de Loyola". En FN IV, 15831605. Roma: MHSI, 1965.

Ricard, Robert. "San Juan de Ávila, inspirador del P. La Palma”. Revista de Occidente XLIX (1975): 191-200.

Rodríguez, Alonso. Tratado de perfección y virtudes cristianas. Barcelona: Imprenta de Pablo Riera, 1861.

Roldán Viller, Alejandro. Introducción a la ascética diferencial. Madrid: Razón y Fe, 1968.

Ruiz Jurado, Manuel. El peregrino de la voluntad de Dios. Biografía espiritual de San Ignacio de Loyola. Madrid: BAC, 2005.

Sheldon, William Herbert. Las variedades del temperamento: psicología de las diferencias constitucionales. Buenos Aires: Paidos, 1972.

Sommervogel, Carlos. Bibliothèque de la Compagnie de Jésus. Vol. VI. Bruxelles, 1895.

Tomás de Aquino. Suma de Teología. 4. a ed. Madrid: BAC, 2001.

Valtierra, Ángel, y Rafael María Hornedo. San Pedro Claver. 2. ${ }^{a}$ ed. Madrid: BAC, 1997.

Vargas Cano de Santayana, Manuel. "La Anotación 15. a de los Ejercicios Espirituales de san Ignacio de Loyola. La rectitud de intención del que da los Ejercicios y su interpretación en algunos comentarios clásicos". Doctorado en el Programa de Historia de la práctica de los Ejercicios Espirituales de san Ignacio, Universidad Pontificia Comillas, Madrid, 2017. Accesible en http://hdl.handle.net/11531/24095 